\title{
RATIONAL CONTAGION AND THE GLOBALIZATION OF SECURITIES MARKETS
}

\author{
Guillermo A. Calvo \\ Enrique G. Mendoza \\ Working Paper 7153 \\ http://www.nber.org/papers/w7153
NATIONAL BUREAU OF ECONOMIC RESEARCH 1050 Massachusetts Avenue
Cambridge, MA 02138
June 1999

We thank V.V. Chari, David Bowman, Rudi Dornbusch, Sebastian Edwards, David Howard, Bob Keohane, Peter Lange, Peter Montiel, Maurice Obstfeld, and Matt Pritsker for helpful comments and suggestions. Comments by seminar participants at the Bank of Mexico, the Board of Governors of the Federal Reserve System, the Federal Reserve Bank of Minneapolis, the 1997 Meetings of the Society for Economic Dynamics, the 1998 Meetings of the American Economic Association and the Conference on Globalization, Economic Reform and Capital Markets Crises held at Duke University December 7-8, 1998 are also gratefully acknowledged. All opinions expressed are those of the authors and not those of the National Bureau of Economic Research.

(C) 1999 by Guillermo A. Calvo and Enrique G. Mendoza. All rights reserved. Short sections of text, not to exceed two paragraphs, may be quoted without explicit permission provided that full credit, including (C) notice, is given to the source. 
Rational Contagion and the Globalization

of Securities Markets

Guillermo A. Calvo and Enrique G. Mendoza

NBER Working Paper No. 7153

June 1999

JEL No.F30, F34, F36, G11, G15

\section{ABSTRACT}

This paper argues that the globalization of securities markets may promote contagion among investors by weakening incentives for gathering costly country-specific information and by strengthening incentives for imitating arbitrary market portfolios. In the presence of short-selling constraints, the utility gain of gathering information at a fixed cost converges to a constant level and may diminish as securities markets grow. Moreover, if a portfolio manager's marginal cost for yielding below-market returns exceeds the marginal gain for above-market returns, there is a range of optimal portfolios in which all investors imitate arbitrary market portfolios and this range widens as the market grows. Numerical simulations suggest that these frictions can have significant quantitative implications and they may induce large capital flows in emerging markets.

Guillermo A. Calvo

Center for International Economics

Department of Economics

University of Maryland

College Park, MD

and NBER

calvo@econ.umd.edu
Enrique G. Mendoza

Department of Economics

Box 90097

Duke University

Durham, NC 27708-0097

and NBER

mendozae@econ.duke.edu 
"If I may be allowed to appropriate the term speculation for the activity of forecasting the psychology of the market, and the term enterprise for the activity of forecasting the prospective yield of assets over their whole life, it is by no means always the case that speculation predominates enterprise. As the organisation of investment markets improves, the risk of the predominance of speculation does, however, increase. ...Speculators may do no harm as bubbles on a steady stream of enterprise. But the position is serious when enterprise becomes the bubble on a whirlpool of speculation." (J. M. Keynes, The General Theory of Employment, Interest, and Money, pp.158-159)

\section{Introduction}

In the aftermath of the Mexican crash of 1994, several emerging stock markets fell as investors "ran for cover," expecting that vulnerable countries like Argentina and Brazil, or even rising stars as Chile or Singapore, would be next in a series of currency crises. ${ }^{1}$ Similarly, the spreading of the financial crisis that originated in Thailand across several countries in East Asia in 1997 and the global financial turmoil triggered by Russia's default in 1998 are widely attributed to unprecedented contagion effects across globalized securities markets. In all these instances, investors seemed to follow the "market" rather than take the time and expense to make their own assessments of each country's fundamentals, perhaps guessing that "market" portfolios embodied relevant information, or fearing the consequences of disagreeing with the "market." A similar phenomenon, albeit at a smaller scale, also appears to operate in the recurrent waves of optimism by institutional investors observed in industrial countries. ${ }^{2}$

The extreme volatility of these speculative capital flows, and the costly economic crises that have accompanied recent financial crashes, have led researchers and policy-makers to reconsider the merits of the trend toward the liberalization of global asset trading that prevailed during the last 15 years. The introduction of controversial capital controls, taxes, and other barriers to asset trading is gaining increasing popularity in the wake of the recent financial turmoil. Chile's taxes and timing restrictions on inflows and outflows of short-term capital, which had been in place since the early 1990s, are an oftencited example of the type of controls that could be useful to prevent contagion. Malaysia's decision to suspend foreign trading in its currency and impose widespread capital controls in 1998 is a more radical

${ }^{1}$ Calvo and Mendoza (1996) review factual evidence of herding by holders of Mexican securities. Calvo and Reinhart (1995) provide some statistical evidence of contagion effects in emerging markets.

${ }^{2}$ See the survey data analysis of contagion by word of mouth by Shiller and Pound (1986) and (1987). 
example. Even at the New York Stock Exchange (NYSE), there are automatic trading halts that stop trading for periods of time during market sessions when stock prices fluctuate too much. However, given that our understanding of the distortions that may produce contagion, and of how these distortions interact with the globalization of capital markets, is very limited, one must remain skeptic about the effectiveness and desirability of these policies.

The aim of this paper is to demonstrate that contagion can be an outcome of optimal portfolio diversification that becomes more prevalent as securities markets grow. Contagion is defined as a situation in which utility-maximizing investors choose not to pay for information that would be relevant for their portfolio decision -- thereby making them susceptible to react to country-specific rumors -- or in which investors optimally choose to mimic arbitrary "market" portfolios. Using a basic framework of mean-variance portfolio diversification, the paper shows that two characteristics of imperfect information can produce equilibria in which incentives for contagion grow stronger as capital markets grow:

(1) If there is a fixed cost of gathering and processing country-specific information, and institutional arrangements or government regulations impose binding short-selling constraints, the utility gain of paying the fixed information cost generally falls as the number of countries where wealth can be invested grows. Portfolio allocations also become more sensitive to changes in asset returns as markets grow, and thus contagion is more likely to prevail and to produce larger capital flows in globalized markets. (2) If portfolio managers face a variable cost or gain that depends on the mean return of their portfolios relative to that of a given market portfolio, and the marginal cost exceeds the marginal gain, there is a range of multiple equilibria inside of which investors rationally choose to mimic market portfolios. When a rumor favors another portfolio in that range, all investors "follow the herd." In this case, globalization exacerbates contagion because the indeterminacy range widens as the market grows.

Since the potential magnitude of contagion effects is largely unknown, and the model proposed here lacks in general tractable analytical solutions, the paper also examines the model's quantitative implications. The quantitative analysis is based on historical data from equity markets and country credit 
ratings (CCRs). Equity-market measures of the mean and variance of country asset returns over a historical period are viewed as free information, while the detailed country expertise imbedded in CCRs is assumed to be costly. Two key empirical regularities are identified in these credit ratings: (a) the ratings of both industrialized and least developed countries are very stable, reflecting the fact that new information does not alter much the perception of investment conditions in these countries, whereas the ratings of emerging economies are very volatile, and (b) information gathering generally leads to larger adjustments of the mean and variance of asset returns, compared to historical equity-market moments, for emerging markets than for OECD countries. Thus, the entry of emerging economies into the global market added investment opportunities for which historical equity-market data were not very informative of future asset returns. The model is calibrated to capture these stylized facts, and simulated to assess the magnitude of the maximum fixed cost agents would pay for country-specific information, and how this maximum is affected by the growth of the global market.

The simulations show that realistic assumptions on the size of the world market, the mean and variance of asset returns, and the information updates provided by CCRs, are consistent with large capital flows driven by contagion. If emerging economies are viewed as a segmented market, our analysis shows that investors rationally choose not to assess the veracity of country-specific rumors if fixed information costs exceed $1 / 5$ of the mean portfolio return prior to the emergence of a rumor. The expected utility gain of information gathering is a steep decreasing function of the number of countries in the portfolio -the full adverse effect of globalization on information gains is transmitted with about a dozen countries. When variable performance costs are considered, there is a range of portfolio shares, measuring about 2.5 percentage points, that supports contagion equilibria even for small costs. Simulations applied to Mexican data suggest that through both fixed- and variable-cost channels the model can rationalize capital outflows exceeding \$15 billion that are unrelated to the country's "fundamentals."

The model examined here does not differentiate global capital markets from domestic stock markets. However, the key distinctive feature of global markets is the fact that information frictions play 
a much larger role in investment decisions than in domestic markets. This is consistent with the empirical regularities identified in country credit ratings, and is also in line with the detailed warnings that securities firms give investors to highlight the special risks of global investing. Advertisements for U.S.-based international mutual funds typically warn of several risks like fluctuations in exchange rates, imposition of withholding taxes, reduced availability of information on non-U.S. firms, political and economic developments, the imposition of capital and exchange controls, differences in regulatory practices and reporting standards, higher volatility and reduced liquidity of foreign securities, and even the possibility of expropriations and confiscatory taxation. The issues of concern to international investors are thus radically different from those that worry domestic investors, and the costs incurred in gaining an expertise at the same level of that typically acquired for domestic investment are much higher (see Frankel and Schmukler (1996)).

Keynes's (1936) classic analysis of "rational speculation," which he defined as "the activity of forecasting the psychology of the market," is an important precursor to our work. Keynes argued that speculation is likely to be more pervasive in larger, better organized markets, as eloquently stated in the quotation that opens this paper. He proposed other mechanisms that could drive speculation -- changes of opinion driven by mass psychology, perverse incentives of professional investors, and changes in the confidence of lenders that finance speculators -- which have been the focus of most of the modern literature on contagion and herding (see, for example, Scharfstein and Stein (1990) and Banerjee (1992)).

The rest of the paper is organized as follows. Section 2 analyses the relationship between contagion and globalization. Section 3 examines the quantitative implications of the model. Section 4 concludes with a discussion of normative issues and suggestions for further research.

\section{Contagion in A Basic Optimizing Framework of Global Portfolio Diversification}

Consider a globalized securities market consisting of $J$ countries $(2 \leq J \leq \infty)$ and a large number of identical investors. The portfolio of the representative investor is to be divided between $J-1$ identical countries and a single country (Country $i$ ) which generally has different asset return characteristics. All 
countries but $i$ pay asset returns that follow i.i.d. processes with mean $\rho$ and variance $\sigma_{\mathrm{J}}^{2}$, which we refer to as the mean and variance of the "world fund." As a result, at equilibrium each one of the $J-1$ countries will be allocated an identical share of the portfolio. Country $i$ pays expected return $r^{*}$ with variance $\sigma_{\mathrm{i}}^{2}$, which is correlated with the world fund according to a correlation coefficient $\eta$. The share of the portfolio invested in the world fund is defined as $\theta$. The investor's preferences are characterized by the following indirect expected utility function:

$$
E U(\theta)=\mu(\theta)-\frac{\gamma}{2} \sigma(\theta)^{2}-\kappa-\lambda(\mu(\Theta)-\mu(\theta)), \quad \gamma, \kappa>0 .
$$

$\gamma$ is the coefficient of absolute risk aversion, $\mu$ and $\sigma$ define respectively the mean and standard deviation of the portfolio as a function of $\theta, \kappa$ represents a fixed cost of acquiring country-specific information, and $\lambda(\mu(\Theta)-\mu(\theta))$ represents the variable performance cost (benefit) of obtaining a mean portfolio return lower (higher) than the mean return of an arbitrary portfolio $\Theta$. The properties of $\lambda$ are specified later.

The objective of this section is to show that both the fixed cost and the performance cost introduce frictions that reduce incentives for information gathering as the globalization progresses (i.e. as $J$ rises). This is done by isolating the effects of each cost on the design of optimal portfolios.

\section{Contagion Driven by Fixed Information Costs and Short-Selling Constraints}

Consider an initial equilibrium in which Country $i$ is identical to the rest (i.e. $r^{*}=\rho$ and $\sigma_{i}=\sigma_{J}=\sigma$ ) and asset returns are uncorrelated $(\eta=0)$, so that the investor allocates equal amounts of wealth across all countries. Assuming, without loss of generality, that he has one unit of wealth, the share of the portfolio invested in each country is $1 / J$ and portfolio mean return and variance are $\rho$ and $\sigma^{2} / J$ respectively.

The investor then hears a "credible" rumor indicating that Country $i$ 's mean return is $r, r \leq r^{*}$, but its variance is still $\sigma^{2}$. The investor can acquire and process country-specific information at the fixed $\operatorname{cost} \kappa$ to assess the veracity of the rumor and update the mean and variance of Country $i$. Assume, for simplicity, that if the investor chooses not to pay $\kappa$, the investor believes the rumor -- the rumor is indeed "credible". Thus, in this case the portfolio choice involves $J-1$ countries with asset return moments $\rho$ and 
$\sigma^{2}$, and Country $i$ with the same variance but expected return $r$. If he pays $\kappa$, asset return characteristics in the $J-l$ countries are unchanged, but the mean and variance of Country $i$ are updated. For analytical tractability, we focus on the case in which the investor that pays $\kappa$ learns the "true" return of Country $i$. Later in the numerical analysis we study the more general case in which he only learns updated values of the mean and variance of Country $i$ returns. ${ }^{3}$ The investor knows that by paying $\kappa$ he will learn a new return $r^{I}$ with zero variance. Before paying $\kappa$, however, the potential update of the return $r^{I}$ is itself a random variable drawn from a known probability distribution function (p.d.f.). ${ }^{4}$ This p.d.f. represents the investor's priors. Clearly, the investor will pay the information cost only if expected utility conditional on costly information, $E U^{I}$, exceeds that conditional on free information, $E U^{U}$ (i.e. the gain from costly information $S \equiv E U^{I}-E U^{U}$ must be positive).

Let $\theta^{\mathrm{U}}$ and $\theta^{\mathrm{I}}$ be the portfolio shares chosen by the investor if he decides to be uninformed or informed respectively. $\theta^{\mathrm{U}}$ is chosen so as to maximize:

$$
E U^{U}=\theta^{U} \rho+\left(1-\theta^{U}\right) r-\frac{\gamma}{2}\left[\frac{\left(\theta^{U}\right)^{2}}{J-1}+\left(1-\theta^{U}\right)^{2}\right] \sigma^{2}
$$

For internal solutions, the corresponding first-order condition implies that the optimal portfolio is:

$$
\theta^{U}=\left(\frac{J-1}{J}\right)\left[1+\frac{\rho-r}{\gamma \sigma^{2}}\right] .
$$

We also assume that optimal portfolios may represent corner solutions because of short-selling constraints. In particular, we assume that $-a \leq \theta^{\mathrm{U}} \leq b$, for given constants $a$ and $b$ such that $0 \leq a<\infty$ and $1 \leq b<\infty$. The case $a=0, b=1$ is the extreme case in which short positions in Country $i$ and the world fund are ruled out. Short-selling constraints imply that $\theta^{\mathrm{U}}=b$ for $r \leq r^{\min }$, where $r^{\min }=\rho-\gamma \sigma^{2}[J(b-1)+1] /(J-1)$,

\footnotetext{
${ }^{3}$ The numerical analysis will cover general cases in which $\mathrm{r}^{*} \neq \rho, \eta \neq 0$, and $\sigma_{\mathrm{i}} \neq \sigma_{\mathrm{J}}$.

${ }^{4} \mathrm{~A}$ consistency condition under rational expectations implies $E\left(r^{I} \mid \kappa\right)=r^{*}$, since $r^{*}$ is an expectation based on free information and the p.d.f. of $r^{I}$ is known. This would make rumors $r<r^{*}$ non-credible. Most of our analysis maintains the consistency condition, but we also examine the effects of arbitrary "credible" rumors.
} 
and $\theta^{\mathrm{U}}=-a$ for $r \geq r^{\max }$, where $r^{\max }=\rho+\gamma \sigma^{2}[J(1+a)-1] /(J-1)$. Note that as $J$ goes to $\infty$, the interval of returns that supports internal solutions for $\theta^{\mathrm{U}}$ shrinks and converges to $r^{\max }-r^{\min }=\gamma \sigma^{2}[b+a]$.

The analysis that follows focuses for simplicity on cases in which $r$ is such that the portfolio conditional on free information features internal solutions. For $r$ in the interval $r^{\min }<r<r^{\max }, E U^{U}$ valued at the maximum is:

$$
E U^{U}=\left(r-\frac{\gamma}{2} \frac{\sigma^{2}}{J}+\frac{(\rho-r)}{2} \frac{J-1}{J}\left[2+\frac{(\rho-r)}{\gamma \sigma^{2}}\right]\right)
$$

We examine next the portfolio problem under the assumption that the investor pays for information. An investor who paid $\kappa$ learns the realization $r^{I}$. State-contingent utility $U^{I}\left(r^{I}\right)$ is:

$$
U^{I}\left(r^{I}\right)=\theta^{I} \rho+\left(1-\theta^{I}\right) r^{I}-\frac{\gamma}{2}\left[\frac{\left(\theta^{I}\right)^{2}}{J-1}\right] \sigma^{2}-\kappa .
$$

For internal solutions, the optimal, state-contingent portfolio is:

$$
\theta^{I}\left(r^{I}\right)=(J-1)\left[\frac{\rho-r^{I}}{\gamma \sigma^{2}}\right] .
$$

For corner solutions, the short-selling constraints imply: $\theta^{\mathrm{I}}\left(r^{I}\right)=a$ if $r^{I} \geq r_{\max }{ }^{I}$ and $\theta^{\mathrm{I}}\left(r^{I}\right)=b$ if $r^{I} \leq r_{\min }{ }^{I}$ where:

$$
r_{\min }^{I}=\rho-\frac{b \gamma \sigma^{2}}{J-1}, \quad r_{\max }^{I}=\rho+\frac{a \gamma \sigma^{2}}{J-1}
$$

It is important to note that these expressions imply that the interval of returns that supports optimal portfolios of an informed investor with internal solutions vanishes as $J$ grows infinitely large. Thus, as the market grows infinitely large, optimal portfolios conditional on costly information always hit the short selling constraints. This plays a key role in producing the result that $S$ can be decreasing in $J$.

Let $F\left(r^{I}\right)$ and $f\left(r^{I}\right)$ denote the c.d.f. and p.d.f. of $r^{I}$. EU $U^{I}$ is therefore given by:

$$
E U^{I}=\int_{-\infty}^{\infty}\left[\theta^{I}\left(r^{I}\right) \rho+\left(1-\theta^{I}\left(r^{I}\right)\right) r^{I}-\frac{\gamma}{2}\left[\frac{\left(\theta^{I}\left(r^{I}\right)\right)^{2}}{J-1}\right] \sigma^{2}\right] f\left(r^{I}\right) d r^{I}-\kappa
$$


We show below that, under fairly general conditions, $S$ falls as $J$ rises for any given $\kappa$. Thus, globalization can reduce the incentives to gather country-specific information.

Proposition 1: For any "pessimistic" rumor such that (i) short-selling constraints are not binding for the portfolio of an uninformed investor $\left(r^{\min }<r<r^{\max }\right)$ and (ii) the rumor sets the Country $i$ return to be less or equal than the return of the world fund $\left(r \leq r^{*}=\rho\right)$, and assuming that both $F$ and $f$ are continuously differentiable, $S$ is decreasing in $J$ (i.e. $d S / d J<0$ ), for $J<\infty$, if the number of countries in the global market is at least $J>1 /\left\{1-\left[F(\rho)\left(b^{2}-a^{2}\right)+a^{2}\right]^{1 / 2}\right\}$.

Proof: State-contingent utility conditional on costly information (net of $\kappa$ ) can take the following values:

If $r^{I} \leq r_{\min }{ }^{I}$ :

$$
U^{I}\left(r^{I}\right)=b \rho+(1-b) r^{I}-\frac{\gamma \sigma^{2}}{2} \frac{b^{2}}{J-1}
$$

If $r_{\min }{ }^{I}<r^{I}<\rho:$

$$
U^{I}\left(r^{I}\right)=r^{I}+\frac{1}{2} \frac{\left(\rho-r^{I}\right)^{2}}{\gamma \sigma^{2}}(J-1) .
$$

If $r^{I} \geq \rho$ :

$$
U^{I}\left(r^{I}\right)=-a \rho+(1+a) r^{I}-\frac{\gamma \sigma^{2}}{2} \frac{a^{2}}{J-1}
$$

Thus, for any rumor in the interval $r^{\min }<r<r^{\max }, S$ is given by:

$$
\begin{aligned}
S & =\left(b \rho-\frac{\gamma \sigma^{2}}{2} \frac{b^{2}}{J-1}\right) F\left(r_{\min }^{I}\right)+\int_{r_{\min }^{I}}^{r_{\max }^{I}}\left[r^{I}+\frac{1}{2} \frac{\left(\rho-r^{I}\right)^{2}}{\gamma \sigma^{2}}(J-1)\right] d F\left(r^{I}\right) \\
& -\left(a \rho+\frac{\gamma \sigma^{2}}{2} \frac{a^{2}}{J-1}\right)\left(1-F\left(r_{\max }^{I}\right)\right)+\int_{\infty}^{r_{\min }^{I}}(1-b) r^{I} d F\left(r^{I}\right)+\int_{r_{\max }^{I}}^{\infty}(1+a) r^{I} d F\left(r^{I}\right)-\kappa \\
& -\left(r-\frac{\gamma}{2} \frac{\sigma^{2}}{J}+\frac{(\rho-r)}{2} \frac{J-1}{J}\left[2+\frac{(\rho-r)}{\gamma \sigma^{2}}\right]\right) .
\end{aligned}
$$

Since $F\left(r^{I}\right)$ is continuously differentiable,

$$
\begin{aligned}
& \frac{d S}{d J}=\frac{\gamma \sigma^{2}}{2(J-1)^{2}}\left[b^{2} F\left(r_{\min }^{I}\right)+a^{2}\left(1-F\left(r_{\max }^{I}\right)\right)\right]+\int_{r_{\min }^{I}}^{r_{\max }^{I}} \frac{1}{2} \frac{\left(\rho-r^{I}\right)^{2}}{\gamma \sigma^{2}} d F\left(r^{I}\right) \\
& -\frac{\gamma}{2} \frac{\sigma^{2}}{J^{2}}-\frac{(\rho-r)}{2 J^{2}}\left(2+\frac{(\rho-r)}{\gamma \sigma^{2}}\right) .
\end{aligned}
$$


Setting $r^{I}=r_{\min }{ }^{I}$ in expression (13), it follows that:

$$
\frac{d S}{d J} \leq \frac{\gamma}{2} \frac{\sigma^{2}}{(I-1)^{2}}\left|b^{2} F(\rho)+a^{2}(1-F(\rho))-\left(\frac{J-1}{J}\right)^{2}\right|-\frac{(\rho-r)}{2 I^{2}}\left(2+\frac{(\rho-r)}{v \sigma^{2}}\right) .
$$

Since $r \leq \rho$, it follows that $1 /\left\{1-\left[F(\rho)\left(b^{2}-a^{2}\right)+a^{2}\right]^{1 / 2}\right\}<J<\infty$ is sufficient (although not necessary) for $d S / d J<0 . \square$

The intuition of the result is straightforward to explain if $r=\rho$, so that the last terms in (13) and (14) vanish. In this case, there is effectively no rumor and the problem can be restated as studying how the value of acquiring information to eliminate the uncertainty of a single asset changes as the number of assets rises. ${ }^{5}$ As $J$ increases, the variance of the world fund falls, making it a more effective means of diversifying risk regardless of whether information about Country $i$ is gathered or not. This can be seen in the right-hand side of (13). The first two terms represent the marginal utility of $J$ conditional on costly information, and the third term is the marginal utility of $J$ conditional on free information. Both are positive but declining functions of $J$. As long as short-selling constraints are present, however, the marginal utility of $J$ conditional on costly information eventually falls behind that conditional on free information. This occurs because short-selling constraints prevent investors from taking full advantage of costly information. If investors could hold arbitrarily large short positions, the marginal utility of $J$ conditional on costly information would be independent of the size of the market (the first term in the right-hand-side of (13) would vanish and the second would be independent of $J$ ). Only the effect of the shrinking marginal utility of $J$ under free information would remain, and hence $d S / d J$ would be increasing in $J$.

The key point of Proposition 1 is that, for any given $\kappa$ and $\rho$, the utility gain derived from costly information decreases as $J$ rises (i.e., the marginal utility of $J$ is negative). This adverse effect of market growth has "decreasing returns," in the sense that $S$ will fall as $J$ rises but at a declining rate. This is

${ }^{5}$ For an insightful analysis of the value of information without short-selling constraints see Pritsker (1994). Our results suggest, however, that the value of information differs sharply when these constraints are present. 
because, as $J \rightarrow \infty, d S / d J$ converges to zero, as the world fund becomes a risk-free asset. Hence, $S$ converges to a constant level independent of $J$ as $J$ grows to infinity. Clearly, that constant utility level could be positive or negative depending on the values of $\kappa$ and $\rho$, which is not an interesting finding. In contrast, the convergence of $S$ in the presence of costly information and short-selling constraints (for any $\kappa$ and $\rho$ ) is a striking result that deviates sharply from the finding that $S$ grows without bound if shortselling constraints do not exist. Hence, if the cost of information were even trivially increasing in $J$, short-selling constraints ensure that for a sufficiently large market information is never paid for.

Proposition 1 also has important policy implications. If the proposition holds, globalization works to weaken incentives for information gathering because it takes place against the background of institutional limitations or government regulations that limit the ability of investors to hold short positions. This argument implies, therefore, that policies aimed at containing market volatility by tightening short-selling constraints have at least one channel for being counterproductive: short-selling constraints contribute to reduce an investor's willingness to acquire costly information.

The sufficiency condition, $J>1 /\left\{1-\left[F(\rho) b^{2}+(1-F(\rho)) a^{2}\right]^{1 / 2}\right\}$, established in Proposition 1 to ensure that $S$ is decreasing in $J$ after some critical $J$ merits some clarification. This condition sets restrictions on the relative values of $a, b$ and $F(\rho)$. Roughly speaking, the condition sets lower bounds on the tightness of short-selling constraints relative to the conditional probabilities that costly information will yield updated Country-i returns greater or smaller than the return of the world fund. A natural interpretation emerges if we label $F(\rho)$ the probability of "bad news" (in the sense that $F(\rho)=\operatorname{Pr}\left\{r^{I} \leq \rho\right\}$ ) and $1-F(\rho)$ the probability of "good news" ( since $1-F(\rho)=\operatorname{Pr}\left\{r^{I} \geq \rho\right\}$ ), keeping in mind that a higher critical $J$ indicates more willingness to pay for costly information since it would take a larger number of countries for $S$ to begin to decrease as $J$ increases. A weaker short-selling constraint on Country $i$ (i.e., higher $b$ ) will make critical $J$ larger, the higher the probability of bad news -- that is, the more likely is that the investor will face states of nature in which short positions on Country $i$ are optimal. Similarly, a weaker short-selling constraint on the world fund (i.e., higher $a$ ) will make critical $J$ larger, the higher is the probability of 
good news -- that is, the more likely is that the investor will face states of nature in which short positions in the world fund are optimal. It must be recalled, however, that the condition established in Proposition 1 is only a sufficiency condition.

It follows from the previous argument that, in general, assessing the relevance of the prediction that $d S / d J$ could be negative can only be determined by assigning values to the model's exogenous parameters, adopting a functional form for $F($.$) and computing numerically the expressions in (12) and$ (13). Numerical simulations are also critical because (12) and (13) reflect a very specialized case in which information reveals true asset returns, instead of just updates of the mean and variance of returns, and asset returns are uncorrelated. We lack analytical results for general cases relaxing these assumptions. A thorough numerical analysis is conducted in Section 3. However, one basic example is still very illustrative of the model's potential. Assume that $a=0, b=1$ and $f$ is a symmetric p.d.f such that $E\left(r^{I}\right)=r=\rho$ (which, since $f$ is symmetric, implies $\left.F(\rho)=0.5\right)$. In this case the sufficiency condition of Proposition 1 reduces to $J>1 /\left[1-0.5^{1 / 2}\right]$, and $d S / d J$ is negative with 4 countries or more. If $F(\rho)$ were smaller (larger) than 0.5, which implies $E\left(r^{I}\right)$ larger (smaller) than $\rho$, the critical $J$ falls (rises). This shows that when investors are "bullish" on Country $i$, in the sense that $E\left(r^{I}\right)>\rho, S$ begins to decrease with $J$ for a smaller market than when investors are "bearish" on Country $i$. When costly information is expected to produce good news, and short-selling constraints severely limit the gains of learning bad news, incentives for buying information are weak. If we relax the short selling constraint on Country $i$, so that $b>1$ while keeping $a=0$, the sufficiency condition changes to $J>1 /\left[1-b 0.5^{1 / 2}\right]$. With $b=1.25$, so that the investor can short Country $i$ for up to 25 percent of his wealth, the critical $J$ increases to 9 . As $b$ approaches $0.5^{-1 / 2}$ the critical $J$ goes to infinity, and the sufficiency condition fails for $b>1.41$.

Expression (13) shows that, in addition to the terms involved in the sufficiency condition, another key determinant of the critical $J$ is the size of the rumor. Consider again the case in which $f$ is symmetric, $a=0$, and $b=1$. A pessimistic rumor such that $r^{\min }<r<\rho$ implies that $d S / d J$ may be negative even if $F(\rho)$ is somewhat larger than $1 / 2$ (i.e. with $r<\rho$, the critical value of $J$ falls for any given $F(\rho)$ ). 
This is because expected utility of uninformed investors rises with the difference $\rho-r$. Thus, a bad rumor contributes to reduce the benefits of gathering information on Country $i$ as the market expands even if investors are bearish about Country $i$ (i.e. $\left.E\left(r^{I}\right)<\rho\right)$.

One important remark. As $J$ rises, not only are incentives to gather information diminishing, but the impact of unverified rumors on the portfolio share assigned to a single country (relative to the initial share $1 / J$ ) grows without bound. This is because $-d 0^{U} / d r$ converges to $1 / \gamma \sigma^{2}$ as $J \rightarrow \infty$. Thus, global market volatility (defined by a shift in $1-\theta^{\mathrm{U}}$ in response to a pessimistic rumor relative to the initial, rumor-free portfolio share $1 / J$ ) increases as $J$ rises, resulting in larger proportional effects on capital flows.

\section{Contagion Driven by Performance-based Incentives}

The effects of rumors we examined above could be short-lived to the extent that they could induce a "price correction" in the affected country's securities markets that can drive expected returns high enough to undo the effect of the rumor. There are, however, several reasons why a price correction may fail to undo the effects of rumors. For instance, if the correction is seen as triggering a very distortionary policy response that will cripple the economy, the market collapse can become part of a self-fulfilling crisis (see Calvo (1996)). Another reason are the performance-based incentives we study next. These incentives produce contagion as a result of multiple equilibria in optimal portfolio shares.

Consider investors, or mutual fund managers, that face a variable cost or benefit of obtaining mean returns that deviate from the mean return of an arbitrary market portfolio, and put aside the fixed information cost by setting $\kappa=0$. The cost function $\lambda(\mu(\Theta)-\mu(\theta))$ satisfies the following properties:

$$
\begin{gathered}
\lambda>0 \text { if } \mu(\theta)<\mu(\Theta), \quad \lambda \leq 0 \text { if } \mu(\theta)>\mu(\Theta), \lambda(0)=0, \\
\lambda^{\prime} \geq 0 \text { with } \lambda^{\prime}(x)>\lambda^{\prime}(-x) \text { for all } x=\mu(\Theta)-\mu(\theta)>0
\end{gathered}
$$

$$
\lambda^{\prime \prime} \leq \mathbf{0}
$$

It is also assumed that $\lambda^{\prime}(0)$ does not exist to capture the notion of fixed costs. The conditions in (15) imply that managers pay a cost (earn a benefit) when the mean return of their portfolios is smaller 
$-13-$

(larger) than that of the market portfolio, and that the marginal cost exceeds the marginal benefit. ${ }^{6}$

The problem of a representative manager is to choose $\theta$, given some $\Theta$, so as to maximize:

$$
\begin{aligned}
E U(\theta)=\theta \rho & +(1-\theta) r-\lambda(\mu(\Theta)-\mu(\theta)) \\
- & \frac{\gamma}{2}\left[\frac{\left(\theta \sigma_{J}\right)^{2}}{J-1}+\left((1-\theta) \sigma_{i}\right)^{2}+2 \sigma_{J} \sigma_{i} \theta(1-\theta) \eta\right]
\end{aligned}
$$

We allow the variances of investing in Country $i\left(\sigma_{\mathrm{i}}^{2}\right)$ and in all $J$ countries except $i\left(\sigma_{\mathrm{J}}^{2}\right)$ to differ, and asset returns are correlated according to the coefficient $\eta$. Also note that, since $\mu(\theta)=\theta \rho+(1-\theta) r$ and $\mu(\Theta)=\Theta \rho+(1-\Theta) r$, it follows that $\lambda(\mu(\Theta)-\mu(\theta))=\lambda((\Theta-\theta)(\rho-r))$.

This portfolio allocation problem displays contagion in the sense that, for rumors within a certain range of values of $\Theta$, choosing $\theta=\Theta$ is optimal for a representative investor and is also a rationalexpectations equilibrium in which all investors select the same portfolio. Any rumor in that range calling for a different $\Theta$ results in a herding panic in which all investors re-set their portfolios to that new $\Theta$.

Proposition 2: If in the neighborhood of the optimal portfolio $0^{*}$ corresponding to an investor free of performance incentives, the marginal cost (gain) of deviating from the mean return of the market portfolio $\mu(\Theta)$ is sufficiently large (small), there exists a range of global, rational-expectations equilibria of individual portfolio allocations 0 , such that investors optimally choose $0=\Theta$.

Proof: We prove that, under certain conditions, the optimal response to a market portfolio $\Theta$ it to set $\theta=\Theta$ because $E U^{\prime}(0)<0$ for $\theta>\Theta$ and $E U^{\prime}(0)>0$ for $\theta<\Theta$. The proof is as follows:

(i) The first-order condition for maximization of (16) with respect to $O$ is:

$$
\rho-r-\gamma\left[\frac{\theta \sigma_{J}^{2}}{J-1}-(1-\theta) \sigma_{i}^{2}+\eta \sigma_{J} \sigma_{i}((1-\theta)-\theta)\right]-\lambda^{\prime}(\cdot)(r-\rho)=0 .
$$

(ii) Define $E \hat{U}^{\prime}(O) \equiv \rho-r-\gamma\left[0 \sigma_{J}^{2} /(J-1)-(1-\theta) \sigma_{i}^{2}+\eta \sigma_{J} \sigma_{i}((1-\theta)-O)\right]$ as the marginal utility of $\theta$ for an investor that does not face performance incentives, so $E \hat{U}^{\prime}\left(0^{*}\right)=0$ at the optimum $\theta^{*}$. Note that the second-order condition $E \hat{U}^{\prime \prime}(0)<0$ requires $\sigma_{J}^{2} /(J-1)+\sigma_{i}^{2}>2 \eta \sigma_{J} \sigma_{i}$.

${ }^{6}$ For a real-world example, consider the case of Chile's private pension funds. Each fund is required by government regulation to produce returns within a certain range of the average return for all pension funds. 
(iii) Given (ii), rewrite (17) as:

$$
\boldsymbol{E} \hat{\boldsymbol{U}}^{\prime}(\boldsymbol{\theta})-\boldsymbol{\lambda}^{\prime}(\cdot)(\boldsymbol{r}-\boldsymbol{\rho})=\mathbf{0}
$$

(iv) The solution(s) to (17) will depend on the relative returns of Country $i$ and the world fund. Clearly, if $r=\rho$ the solution $\theta^{*}$ will also be the unique solution for the model with performance costs, and there is no contagion. Thus, the relevant cases are those in which $r$ and $\rho$ differ.

(v) Consider the case in which $r>\rho$ and assume an arbitrary market portfolio such that $\Theta \leq \theta^{*}$. Investors will not choose $\theta>\Theta$ if it implies $E U^{\prime}(0)<0$. There are two options. First, if $\theta>\theta^{*}$ clearly $E U^{\prime}(0)<0$ because $E \hat{U}^{\prime}(0)<0$, as implied by $E \hat{U}^{\prime}\left(0^{*}\right)=0$ and $E \hat{U}^{\prime \prime}(0)<0$, and $\lambda^{\prime}(\cdot)(\mathrm{r}-\rho)>0$. Second, if $\Theta<\theta \leq \theta^{*}$, a necessary and sufficient condition for $E U^{\prime}(\theta)<0$ is $\lambda^{\prime}(\cdot)(r-\rho)>E \hat{U}^{\prime}(0)$. Since with $\mathrm{r}>\rho$ and $\theta>\Theta$ the investor would obtain a mean return smaller than that of the market portfolio, this condition states that the marginal cost of producing below-market returns needs to be "sufficiently large" in the vicinity of $\theta^{*}$ for equilibria with contagion to exist. A similar condition ensures that investors will not choose $\theta<\Theta$ (i.e. $E U^{\prime}(\theta)>0$ if $\left.\theta<\Theta\right)$. For such a $\theta, \theta<\Theta \leq \theta^{*}$, and $\theta<\theta^{*}$ implies $E \hat{U}^{\prime}(\theta)>0$. Thus, $E U^{\prime}(\theta)>0$ if $E \hat{U}^{\prime}(\theta)>\lambda^{\prime}(\cdot)(r-$ $\rho$ ). Note that in this case the investor would be beating the market by setting $\theta<\Theta$, so this condition states that in the neighborhood of $\theta^{*}$ the marginal gain of beating the market must be "sufficiently small" for contagion equilibria to exist. Finally, note there are is contagion for $\Theta \geq \theta^{*}$ because the condition that $E U^{\prime}(0)>0$ for $\theta<\Theta$ can never hold if $\theta^{*} \leq \theta<\Theta$. In this case, $E \hat{U}^{\prime}(\theta) \leq 0$ and $\lambda^{\prime}(\cdot)(r-\rho)>0$, so $E U^{\prime}(0)<0$. (v) An argument similar to (iv) shows that for $r<\rho$ there is a range of contagion equilibria for some values of $\Theta$ in the region $\Theta \geq \theta^{*}$, if $E \hat{U}^{\prime}(\theta)<\lambda^{\prime}(\cdot)(r-\rho)$ for $\theta>\Theta$ and $E \hat{U}^{\prime}(\theta)>\lambda^{\prime}(\cdot)(r-\rho)$ for $\theta^{*} \leq \theta<\Theta$. In this case, there can be no contagion equilibria in the range $\Theta \leq \theta^{*}$. $\square$

The result in Proposition 2 is interesting, although it hinges critically on the assumption that, at the margin, poor performance is punished more than good performance. We are also interested in a second result showing that in the presence of these performance costs it is again the case that globalization strengthens incentives for contagion. The latter is implied by the fact that the range of contagion equilibria widens as the global market grows for a given performance cost function. 
Proposition 3. The range of contagion equilibria, defined by the values of $\Theta$ in the interval $0^{\text {low }}<\Theta<0^{u p}$ for which Proposition 2 holds, widens as the global market grows (i.e. $0^{u p}-O^{\text {low }}$ is increasing in J).

Proof: To simplify this proof we consider the case of a linear marginal cost function, so $\lambda^{\prime \prime}(\Theta-\theta)=0$, and limit our attention to the case in which $r>\rho$, which are the assumptions adopted in the numerical exercise of the next section. Note that in this case $\partial^{\text {low }}$ satisfies (17) for $\mu(\Theta)>\mu(O)$ and $\partial^{\prime p}$ satisfies (17) for $\mu(\Theta)<\mu(0)$. The total differential of (17) implies that:

$$
\frac{d \theta}{d J}=\frac{\left(\frac{\gamma \theta \sigma_{J}^{2}}{(J-1)^{2}}\right)}{\gamma\left(\frac{\sigma_{J}^{2}}{J-1}+\sigma_{i}^{2}-2 \eta \sigma J \sigma i\right)}
$$

The expression in the denominator of (19) corresponds to $-E \hat{U}^{\prime \prime}(O)$, and thus as long as the second-order condition stated in (ii) above holds, $d O / d J$ is positive and increasing in $\theta$. It follows that as $J$ rises both $\partial^{a p}$ and $\theta^{\text {low }}$ rise, and, since $\partial^{a p}>\partial^{\text {low }}, \partial^{a p}$ rises more than $\partial^{\text {low }}$, so the range of multiple equilibria widens.

The intuition for this result is simple. Given a marginal cost invariant to $J$ or $\theta$, the growth of the market affects the expected marginal utility of optimal portfolios in two ways. First, as $J$ rises, the effective variance of the world fund $\left(\sigma_{J}^{2} /(J-1)^{2}\right)$ falls for given holdings of that fund, and thus the marginal utility of $\theta$ rises. This effect is proportional to the portfolio share invested in the world fund, as shown in the numerator of (19). Second, the reduced variance of the world fund makes it a more attractive asset relative to Country $i$, providing an incentive to increase $\theta$, which in turn reduces marginal utility. This second effect is independent of $\theta$ because the rate at which marginal utility falls as $\theta$ rises is invariant to portfolio shares, as the denominator of (19) shows. Hence, the optimal portfolio shift induced by an increase in $J$ is larger the larger the initial $\theta$. Notice, however, that $d 0 / d J$ is decreasing in $J$ and converges to 0 as $J$ goes to infinity because in a large market the world fund becomes virtually riskless. Thus, like the adverse effect of $J$ on $S$ in the fixed-cost case, the magnifying effect of $J$ on the contagion range displays "diminishing returns." 
All portfolios inside the contagion range are sub-optimal, except in particular cases in which the Pareto-efficient portfolio $\theta^{*}$ is inside the range. ${ }^{7}$ Thus, contagion is generally inefficient. Moreover, the existence of multiple optimal portfolios for a given pair of mean returns $r$ and $\rho$ implies that there can be capital outflows from Country $i$ even in the absence of rumors about country asset returns. This also implies that a price correction following a rumor about $r$ may not prevent persistent contagion effects.

\section{A Comparison with Game-Theoretic Models of Contagion and Herding}

The framework presented above considers a global market consisting of a large number of identical investors formulating simultaneous decisions. This differs sharply from the sequential decisionmaking setup typical of game-theoretic models of herd behavior. ${ }^{8}$ These models show that when information is incomplete, and the signals that transmit it are noisy, agents waiting in line to make a decision may imitate agents ahead of them, rather than use their own information (a situation referred to as an "informational cascade" that leads to herding).

Our framework could be easily incorporated into a sequential decision-making setting. Consider the case in which information can be acquired at a fixed cost. ${ }^{9}$ Assume a group of $N$ investors, indexed $h=1, . . N$, making portfolio choices in sequence. Each draws a noisy signal (i.e. a rumor) about $r$ denoted $r_{h}$ which cannot be observed by the other $N-1$ investors, although portfolio choices are public information. Whenever an investor pays the information cost, he learns the true value $r^{I}$. Start with the choice of the first investor in a small market. Assume $S>0$, so that he pays the information cost. In this case the initial rumor does not prevail. Let $J$ rise, so $S$ begins to decline until $S<0$. Now the first investor does not pay for the information that would discredit the rumor. Moreover, assume that his signal is

${ }^{7}$ This is because $\theta^{*}$ maximizes $E \hat{U}(0)$, and $E U(0)=E \hat{U}(0)$ whenever $\theta=\Theta$ since $\lambda(0)=0$.

${ }^{8}$ Our analysis shares with the game-theoretic models of Banerjee (1992) and Bikhchandani et al. (1992) the need to assume two sources of uncertainty. They assume uncertainty about outcomes and private signals, while our fixed-cost model assumes uncertainty about ex ante asset returns and about updates of mean and variances of assets returns.

${ }^{9} \mathrm{~A}$ similar example can be constructed for the case with performance costs, if they are viewed as the "sharing-the-blame" reputational effects that induce herding externalities in Scharfstein and Stein (1990). 
$r_{1}<r^{\min }$, so his portfolio choice is $\theta^{U}=1$. This conveys the information that $r_{1}<r^{m i n}$ to all investors after him. Given an initial negligible prior against Country $i$, if all investors after the first get signals $r_{h}>r^{\min }$, for $h=2 \ldots N$, and if signals are of the same quality (as in the restaurants example of Banerjee (1992)), all investors go by the prior and choose $0=1$, disregarding private signals favoring Country $i$. The information cost is never paid and all investors hold the same portfolio reacting to the initial rumor.

The "informational cascades" models require the assumption that investors choose their portfolios in a well-organized sequential setting, which seems at odds with the simultaneous sell offs observed recently in global capital markets. The models also feature equilibria in which private information is not discarded (i.e., depending on the ordering in which sequential decision-makers are lined up, there are "informational cascades" without herding). As a result, the origin of herding is not just in information differences across investors, or in their willingness to acquire new information, but depends critically on the ordering in which a set of investors arrive in the market to make their decisions.

The contagion models examined by Shiller (1995) also have an interesting connection with our model. Contagion by word-of-mouth provides microfoundations for the process leading from one value of $\Theta$ to another and for rumors regarding the value of $r$. There is ample anecdotal evidence of word-ofmouth contagion in the spreading of rumors during the Mexican crisis. One dramatic example was the sharp fall of the peso in November 11, 1995, triggered by the rumors of a coup and the resignation of the finance minister, both of which originated in U.S. capital markets (see Calvo and Mendoza (1996)). The rumors were quickly discredited, but the peso recovered only a small fraction of its losses.

\section{Numerical Simulations}

This section examines the quantitative implications of the model. The objective of the exercise is not to test the model's ability to explain actual investment behavior, but simply to explore the potential magnitude of the effects that result from the informational frictions we studied analytically in Section 2.

\subsection{Benchmark Calibration and Stylized Facts}

The numerical analysis starts from a benchmark designed to mimic two sets of stylized facts: 
$-18-$

(A) Composition of global portfolios and statistical moments of asset returns:

The calibration determines a value of the coefficient of absolute risk aversion, $\gamma$, consistent with existing estimates of the mean and variance-covariance structure of asset returns, and data on net holdings of foreign equity by global investors, assuming a conventional mean-variance setup without information or performance costs. The equation that relates $\gamma$ to $\theta$ and the statistical moments of asset returns is derived by solving (17) for $\gamma$ setting $\lambda^{\prime}(\cdot)=0$. We plugged various estimates of the mean and variance-covariance structure of asset returns and the composition of global portfolios from different sources in the resulting expression, and concluded that plausible values of $\gamma$ range between near 0 and 0.5. ${ }^{10}$ We chose the middle point 0.25 for the benchmark. Note, however, that there are also several data combinations that produce negative values of $\gamma$, highlighting the flaws of the mean-variance model.

One example of the above calculations is as follows. Consider a two-country world consisting of the United States and "the rest of the world" as defined in Bohn and Tesar (1994). ${ }^{11}$ This implies the following settings: (1) $\rho=0.62$ percent and $\sigma_{J}=4.46$ percent, which are the mean and standard deviation of monthly excess returns on U.S. equity for the period January 1981-October 1993, (2) $r=0.69$ percent, $\sigma_{i}=5.41$ percent, and $\eta=0.462$, which are the "rest-of-the-world's" mean, standard deviation and U.S.correlation of asset returns, measured in U.S. dollars and assuming unhedged currency risk, and (3) $0=0.964$, which reflects the average holdings of foreign equity by U.S. investors measured at less than 4 percent of their portfolios. These parameters imply $\gamma=0.004$.

(B) Indicators of international information and their impact on asset return assessments

The best publicly-available measure of country-specific information is embodied in existing estimates of country credit ratings. In our simulations we use the credit ratings constructed by

\footnotetext{
${ }^{10}$ See, for example, Bohn and Tesar (1994), Lewis (1995), and Tesar and Werner (1994).

${ }^{11}$ Bohn and Tesar (1994) examined net purchases of foreign stocks by U.S. investors in 17 industrial countries (Australia, Austria, Belgium, Germany, Spain, France, Italy, Netherlands, Switzerland, the U.K., Ireland, Japan, Canada, Denmark, Finland, Norway, Sweden, and South Africa) and 4 emerging markets (Hong Kong, Mexico, Singapore, and Malaysia). They measured returns in dollars relative to the U.S. Tbill.
} 
$-19-$

international banks for their lending operations, and compiled and published every six-months, in March and September, by the Institutional Investor. We examined these CCRs to assess how much investors may find investment conditions to have changed in individual countries every time they gather new information. Figure 1 plots the time-series average of each country's CCR against the corresponding standard deviation, using data for the period September, 1979 to March, 1996. Figure 2 is a similar plot that includes only OECD and Latin American countries.

One key stylized fact that emerges from Figures 1 and 2 is that innovations to CCRs at the semestral frequency are much larger in emerging markets than they are in either industrialized or leastdeveloped economies. The variability of credit ratings is very low both in countries that represent "good risks" (i.e. those with average CCRs exceeding 80, as in the OECD) and in countries that are "bad risks" (i.e. those with CCRs lower than 20, as several countries in Sub-Saharan Africa), while the variability of CCRs is much higher in countries that represent "moderate risks" (i.e. emerging markets). This evidence suggests that when asset trading restrictions among industrial countries were lifted in the 1980s, the newly-created global market consisted of countries of roughly similar risk quality, and where investment conditions were relatively uniform and stable over time. In contrast, the globalization of equity markets in the 1990s expanded to emerging markets where not only asset returns are intrinsically more risky, but where information gathered on economic, social, and political issues results in much larger innovations to credit ratings than in OECD countries.

In order to proceed with the simulations, we also need a framework for mapping the information of the CCRs into probability distributions from which updates of means and variances of asset returns are drawn once $\kappa$ is paid. This mapping is derived from a framework proposed by Erb et al. (1996) to estimate the mean and variance of asset returns in 80 countries for which CCRs exist but equity markets do not exist. These authors examined the relationship between the mean and variance of asset returns and the information captured by CCRs in countries with equity markets. Robust log-linear relationships were estimated and used to forecast moments of asset returns in countries without equity markets. 
Erb et al. (1996) estimated panel regressions of the form $x_{h t+1}=\alpha^{x}+\beta^{x} \operatorname{Ln}\left(C C R_{h t}\right)+u_{h t+1}^{x}$, where $x=$ the semestral mean $(\mu)$ or standard deviation $(s d)$ of asset returns in country $h$. Thus, assuming normal distributions of the variables involved, and standard homogeneity assumptions across country elements in the panel, the moments that describe these distributions are: $E\left[r_{h}^{I}\right]=\alpha^{u}+\beta^{u} E\left[\operatorname{Ln}\left(C C R_{h}\right)\right]$, $E\left[\sigma_{h}^{I}\right]=\alpha^{s d}+\beta^{s d} E\left[\operatorname{Ln}\left(C C R_{h}\right)\right], \sigma_{r h}^{I}=\left(\beta^{u}\right)^{2} \operatorname{VAR}\left[\operatorname{Ln}\left(C C R_{h}\right)\right]+\sigma_{u}^{\mu}{ }^{2}$, and $\sigma_{\sigma}^{I}=\left(\beta^{s d}\right)^{2} V A R\left[\operatorname{Ln}\left(C C R_{i}\right)\right]+\sigma^{s d}{ }_{u}^{2} \cdot{ }^{12}$

The magnitude of the updates of the mean and variance of returns that this framework can produce is illustrated in Figure 3. This chart plots updates of the mean and standard deviation of returns for each country with an equity market in the sample of Erb et al. (1996) based on the September, 1996 CCRs against each country's CCR. Updates are measured as a difference relative to statistical moments based on historical equity-market data (also from Erb et al.). The chart shows that new information arriving in September, 1996 generally resulted in positive updates of mean returns and reduced estimates of the variability of returns. Emerging markets with CCRs between 20 and 70 showed larger upward adjustments in expected returns, and larger downward revisions in standard deviations of returns, while updates for OECD countries were generally small.

It is important to note that although the Institutional Investor provides CCRs at a trivial cost, the information imbedded in them is not free from the perspective of our model. CCRs are costly at the relevant moment in which investors need the information. These costs are incurred by the banks that generate individual credit ratings for lending decisions long before the Institutional Investor aggregates and publishes them. Banks act immediately on the information they collect and process, and their individual ratings only become partially public in the aggregate published ratings.

\subsection{Fixed Information Costs and the Growing Disincentive for Information Gathering}

The quantitative analysis of the fixed cost setup is based on graphs of the expected utility gain of paying for information gross of the fixed cost, $\hat{S}=S+\kappa . \quad \hat{S}$ can also be interpreted as the maximum fixed

\footnotetext{
${ }^{12} \mathrm{~A}$ Table listing these moments for a large sample of countries computed using the regression coefficients from Erb et al. (1996) and the actual CCR data is available from the authors on request.
} 
information cost investors would be willing to pay in terms of mean portfolio return (i.e., $\kappa^{\max }$ such that $\left.S\left(\kappa^{\max }\right)=0\right)$. Since we are dealing with a fixed cost, clearly $d S / d J=d \hat{S} / d J$.

The simulations proceed using the following expression for $E U^{I}$ :

$$
\begin{aligned}
E U^{I}+\kappa & =\int_{-\infty}^{\infty} \int_{-\infty}^{\infty} \theta^{I}\left(r^{I}, \sigma_{i}^{I}\right) \rho+\left(1-\theta^{I}\left(r^{I}, \sigma_{i}^{I}\right)\right) r^{I} \\
& -\frac{\gamma}{2}\left[\frac{\left(\theta^{I}\left(r^{I}, \sigma_{i}^{I}\right) \sigma_{J}\right)^{2}}{J-1}+\left(\left(1-\theta^{I}\left(r^{I}, \sigma_{i}^{I}\right)\right) \sigma_{i}^{I}\right)^{2}+2 \sigma_{J} \sigma_{i}^{J} \eta \theta^{I}\left(r^{I}, \sigma_{i}^{I}\right)\left(1-\theta^{I}\left(r^{I}, \sigma_{i}^{I}\right)\right)\right] f\left(r^{I}\right) g\left(\sigma_{i}^{I}\right) d r^{I} d \sigma_{i}^{I} .
\end{aligned}
$$

where $f$ and $g$ are normal probability distribution functions and $\theta^{\mathrm{I}}\left(\mathrm{r}^{\mathrm{I}}, \sigma_{\mathrm{i}}^{\mathrm{I}}\right)$ is the optimal portfolio conditional on learning updates $\left(\mathrm{r}^{\mathrm{I}}, \sigma_{\mathrm{i}}^{\mathrm{I}}\right)$. The simulations allow $J$ to vary from 2 to 3000 countries, and consider three values of rumors about the Country $i$ return, $r=\left(r^{\text {low }}, \rho, r^{\text {high }}\right)$, where $r^{\text {low }}\left(r^{\text {high }}\right)$ is the minimum (maximum) Country- $i$ return that supports an internal solution for $\theta^{\mathrm{U}}$ when $J=2$ and Country $i$ and the world fund are uncorrelated. The double integral in (20) is computed by Gauss-Legendre quadrature. Integration limits are adjusted gradually, starting from limits equal to $\pm 2 \sigma_{\mathrm{r}}{ }^{\mathrm{I}}$ and $\pm 2 \sigma_{\sigma}{ }^{\mathrm{I}}$, until the double integral captures 98 percent of the joint c.d.f. of $r^{I}$ and $\sigma_{\mathrm{i}}^{\mathrm{I}}$. The short-selling constraints are set initially at $a=0$ and $b=1$, and the effects of relaxing both constraints are examined later.

\section{Case I.- Identical Ex Ante Returns and "Truth-Revealing" Information in the OECD}

The simulations begin by exploring the quantitative implications of the basic case discussed in Section 2, in which $a=0, b=1$, and $F(\rho)=0.5$ (i.e., $E\left(r^{I}\right)=\rho$ ), calibrated to data for relatively stable OECD markets. The basic case also required the assumptions that: (a) asset returns are uncorrelated, $\eta=0$, (b) ex ante all countries are identical, $r^{*}=\rho$ and $\sigma_{i}=\sigma_{J}$, and (c) costly information reveals the true Country- $i$ asset return, $E\left[\sigma_{i}^{I}\right]=\sigma_{\sigma}^{I}=0$. Note that since all countries are identical initially, the scenario in which $r=\rho=r^{*}$ is the variant of the basic case in which $\hat{S}$ measures simply the value of information to eliminate the uncertainty of one asset in the portfolio (since $r=r^{*}$, there is in fact no rumor). The basic case also satisfies the consistency condition under rational expectations (i.e., $\left.E\left(r^{I}\right)=r^{*}\right)$. 
The values of $\rho, \sigma_{J}$, and $\sigma_{i}^{\mathrm{I}}$ are set to $\rho=15.31$ percent, $\sigma_{J}=22.44$ percent, and $\sigma_{i}^{\mathrm{I}}=6.46$ percent respectively. The first two moments are arithmetic averages of the annualized mean and standard deviation of monthly stock returns in U.S. dollars over the period 1979-1995 for OECD countries with "stable markets," and the third moment is an average of the estimates of $\sigma_{h}^{\mathrm{I}}$ computed using the regression coefficients from Erb et al. (1996) as explained earlier. "Stable OECD markets" include OECD members during the entire 1979-1995 period for which the standard deviation of returns did not exceed 30 percent. This excludes Greece, New Zealand, Portugal, and Turkey.

Figure 4 plots $\hat{S}$ for $J$ up to 100 countries, although the simulations ran to $J=3000$ to confirm the convergence of $\hat{S}$. The plot confirms Proposition 1. $\hat{S}$ is decreasing in $J$ for pessimistic rumors such that $r \leq \rho$ (i.e. $r=r^{\text {low }}, \rho$ ) and is increasing in $J$ for the optimistic rumor $r=r^{\text {high }} . \hat{S}$ is decreasing in $J$ even for $J<4$ reflecting the fact that the condition established in Proposition 1 is only a sufficiency condition. If, for instance, $\sigma_{i}^{I}$ is increased from 6.46 to $500, \hat{S}$ is increasing in $\mathrm{J}$ for $\mathrm{J}<4$, but for higher $J$ it becomes decreasing as indicated by the sufficiency condition.

In this basic case, investors facing rumors such that $r \leq \rho$ are willing to pay hefty information costs exceeding 30 percent of mean portfolio return for $J=2$. As $J$ grows to about a dozen countries, $\hat{S}$ falls sharply but still converges to a relatively large amount of 3.7 percent. Thus, for large $J$, the maximum fixed information cost investors would pay is roughly $1 / 3$ of the initial mean portfolio return (15.3 percent). Still, only 12 countries are required for the adverse effect of globalization on information gains to be in full force, and this effect cuts information gains by a factor of 8.6.

To assess the sensitivity of these results to the short-selling constraints, a set of simulations were conducted for the $r=\rho$ scenario by setting $a=\varepsilon, b=1+\varepsilon$, for $\varepsilon=\left(0,0.05,0.1,0.5,1,10,10^{9}\right)$. A value of $\varepsilon=0.5$, for example, implies that investors are allowed short positions in which their holdings of the world fund or Country $i$ exceed their total wealth by up to 50 percent. The results showed that Figure 4 remains essentially unaltered for up to $\varepsilon=0.5$. When $\varepsilon=1, \hat{S}$ is moderately increasing in $J$ for $50<J<100$ and converges to about 8 percent, which is still significantly lower than the starting point of 32 percent for 
$J=2$. When $\varepsilon=10$, the increasing segment is larger and the rate of increase higher, with $\hat{S}$ converging to about 45 percent. The last case, $\varepsilon=10^{9}$, approximates the scenario without short-selling constraints, so $\hat{S}$ converges to a linear function with positive slope. Hence, this analysis suggests that the predictions of the model are fairly robust to the levels of short-selling constraints, unless the latter are assumed to be unrealistically weak. ${ }^{13}$

\section{Case II.- Identical Ex Ante Returns with OECD Information Updates}

Next we focus on the case in which information cannot reveal true asset returns. Hence, investors only learn updates of the mean and variance of returns when they pay $\kappa$. The experiment is calibrated again to "stable" OECD markets, incorporating now the mean and variance of updates of the Country $i$ mean return and its standard deviation. This is done by computing arithmetic averages for the relevant countries again applying the formulae from Erb et al. (1996). This implies setting: $E\left(r^{I}\right)=15.18$, $E\left[\sigma_{i}^{I}\right]=21.81, \sigma_{r}^{I}=6.46$, and $\sigma_{\sigma}^{I}=1.84$. We maintain the assumptions that ex ante all countries are perceived to be identical, so $r^{*}=\rho$ and $\sigma_{i}=\sigma_{J}$, and that asset returns are uncorrelated. The first assumption is not too unrealistic for the group of countries considered, but the second is seriously at odds with the data and hence is relaxed below.

Figure 5 plots $\hat{S}$ for Case II. A comparison with Figure 4 shows that expected utility conditional on costly information is significantly smaller when information cannot reveal true asset returns. In the case of the neutral rumor $r=r^{*}=\rho$ (the middle panels of Figures 4 and 5), $\hat{S}$ falls from 32 to 1 percent for $J=2$, and from about 3.7 to 0.15 percent with $J \geq 20$. A cost of 0.15 percent is 0.6 percent of the ex ante mean return of the portfolio $\left(r^{*}=\rho=15.31\right)$, so in this circumstances investors are significantly more reluctant to pay information costs than in the previous case. Only in the presence of very pessimistic rumors in small markets, investors are still willing to pay large information costs -- $r^{\text {low }}$ for $J=2$ is -110.6

\footnotetext{
${ }^{13}$ Aiyagari and Gertler (1998) report that the maintenance requirement on stocks purchased on margin debt is 0.25 and that the effective margin constraint on futures and options trading is between 0.15 and 0.2 .
} 
percent, and in this case $\hat{S}$ exceeds 32 percent, as shown in the top panel of Figure 5. Moreover, in a market with at least 20 countries, $\hat{S}$ converges to less than 0.45 percent for any rumor $r^{\text {low }} \leq r \leq \rho$.

We consider next the fact that the actual correlation of asset returns is not zero, as we have assumed so far. The correlation of returns across stable OECD markets ranges from 0.3 to 0.6 (see Bohn and Tesar (1996), Lewis (1995) and Erb et al. (1996)). Thus, we simulate the model by setting $\eta=0.35{ }^{14}$ Positive correlation in returns across Country $i$ and the world fund yields even smaller gains of information gathering, with the value of $\hat{S}$ for $r^{\text {low }}$ and $J=2$ falling from 32 to 22 percent. This seems natural because of the implicit assumption that the asset returns of the $J-1$ countries in the world fund are uncorrelated. As a result, when positive correlation between Country $i$ and the world fund is allowed, the assets in the world fund provide better diversification opportunities and this undermines the gains of gathering information on Country $i$. This finding is not modified significantly if the experiment is altered to introduce also correlation of returns across countries in the world fund at the same level of 0.35 .

Thus, from a quantitative standpoint, taking into account the fact that returns across OECD countries are positively correlated works to strengthen disincentives to pay country-specific information costs.

Case III.- Segmented Emerging Markets

The global capital market includes today a growing list of emerging markets which are often viewed as a group segmented from stable OECD markets. In this context, the question to ask may be whether it is optimal to acquire information about a single country when most of the $J-1$ countries are also volatile emerging markets. To simulate this scenario, we consider a case in which all countries are identical emerging markets ex ante, with probabilistic parameters set using arithmetic averages for the Latin American countries with equity markets in the sample of Erb et al. (1996) -- Argentina, Brazil, Chile, Colombia, Mexico, Peru and Venezuela. The resulting parameterization is: $E\left(r^{I}\right)=33.12$, $E\left[\sigma_{i}^{I}\right]=34.57, \sigma_{r}^{I}=49.31, \sigma_{\sigma}^{I}=14.04, r^{*}=\rho=31.21$, and $\sigma_{i}=\sigma_{J}=50.03$.

\footnotetext{
${ }^{14}$ Given the means and variances of asset returns, and the value of $\gamma$, higher correlation coefficients would violate the second-order conditions of the optimization problems of informed and uninformed investors.
} 
The plot of $\hat{S}$ in Figure 6 shows that, when $r=\rho$, the maximum fixed information cost agents are willing to pay declines to about 7 percent for $15 \leq J \leq 300$. This cost represents about $1 / 5$ of the ex ante mean portfolio return (which is now 31.2 percent). Information gains continue to fall very sharply as the market grows, and the adverse effect of market growth on $\hat{S}$ is nearly fully transmitted with about 20 countries. In sharp contrast with Cases I and II, however, $\hat{S}$ does not converge to a positive constant. It reaches a minimum at $J=58$ and then it becomes an increasing function of $J$. Still, it takes a market with at least 500 countries to reach a point where a modest reversal of the initial sharp decline in $\hat{S}$ can be noticed. These results are again robust to a significant relaxation of short-selling constraints. With short-selling constraints set to allow short positions as large as 100 percent of wealth (i.e., $a=1, b=2), \hat{S}$ reaches a minimum of 7.6 percent at $J=25$, and it takes about 400 countries for a modest reversal of the sharp initial fall to be noticeable.

Case III assumes that new information yields average updates of the mean and standard deviations of returns equivalent to 1.06 and 0.69 of the corresponding moments computed with historical equity market data. However, Figure 3 showed that updates vary widely across countries. For instance, in the cases of Argentina, Colombia, Philippines, Taiwan and South Africa, information produced sharply lower expected returns than equity market data, while updates of the standard deviation vary from sharp reductions to moderate increases. In Colombia's case, for example, the average update of the mean return is 0.77 of the equity market forecast, while the standard deviation of returns is virtually the same with or without gathering information. Our model predicts that in this case the value of $\hat{S}$ for a neutral rumor $r=r^{*}$ is 7 percent if $J=2$. As the market grows to include 20 countries, $\hat{S}$ falls to about 0.5 percent for any rumor $r^{\text {low }} \leq r \leq r^{*}$. With the ex ante mean portfolio return at 31.2 percent, this implies that investors in a large market will not pay costs exceeding only 1.6 percent of the ex ante return.

\section{Capital Flows}

We quantify next the capital flows that may take place when investors react to rumors. Consider a situation in which investors may liquidate the assets of an emerging market to seek the "safety" of 
OECD markets. The model is simulated setting parameters so that the $J-1$ countries represent again stable OECD markets and Country $i$ is calibrated to Mexico using the corresponding data and formulae from Erb et al. (1996). In this scenario, if $\kappa>6.5$ percent (or about $2 / 5$ of the ex ante mean portfolio return of 15.4 percent), pessimistic rumors about Mexico would prevail. A rumor that reduced the expected return on Mexican equity from the equity market forecast of 22.4 percent to the level of the OECD mean return of 15.3 percent leads to a reduction in the share of the world portfolio invested in Mexico from 1.7 percent to 0.7 percent -- a reduction of 40 percent. According to the Bolsa de Valores de Mexico (the Mexican stock exchange), direct foreign holdings of Mexican equity exceeded $\$ 50$ billion by the end of 1997, so a 40 percent cut implies an outflow of about $\$ 20$ billion. ${ }^{15}$ A very large amount for a country where central bank foreign reserves exceed that figure by a narrow margin. Note, however, that this calculation does not take into account any correction of prices within the stock market, which would imply that the dollar value of the liquidated stock would likely fall sharply, and hence the ensuing capital outflow would be smaller. Still, even if price adjustments cut the capital outflow by 75 percent, the residual $\$ 5$ billion remains a large figure similar in magnitude to the large speculative attacks against the Mexican peso in March, November and December of 1994. Moreover, as argued in Section 2, price corrections may not contain the effects of rumors if there is multiple equilibria in portfolios shares.

\subsection{Performance Costs and Multiple Optimal Portfolios}

The simulations conclude with an analysis of the multiplicity of optimal portfolios resulting from performance costs. We maintain the settings of the last example involving Mexico and the OECD. The variable performance cost function is of the form: $\lambda=\varphi(\mu(\Theta)-\mu(\theta))$ with $\varphi=15$ for $\mu(\Theta)>\mu(\theta)$ and $\varphi=$ 0 otherwise. The sensitivity of the results to the value of $\varphi$ is examined later.

The solution is illustrated in Figure 7. The solid, upward-sloping line is expected marginal utility without performance costs plotted as a function of the share of the portfolio invested in Mexico $\left(E \hat{U}^{\prime}(1-0)\right.$

\footnotetext{
${ }^{15}$ Quoted in the Mexican newspaper Reforma, 1/15/1998, p. 1A, citing as source the Mexican stock exchange.
} 
in the notation of Section 2), and for $J=2$. The horizontal dotted lines represent the constant marginal cost (gain) of producing below-market (above-market) mean returns (i.e., $\varphi$ ). The lower and upper bounds of the contagion range are delimited by the intersections of $E \hat{U}^{\prime}(1-0)$ with the marginal cost and gain lines. If the market calls any portfolio to the right (left) of the lower (upper) bound, Proposition 2 holds and the investor's optimal choice is to mimic the market. The plot shows that, when $J=2$, the share of portfolio invested in Mexico may fluctuate between 20.2 and 22.5 percent, or about 2.3 percentage points, simply as a result of contagion driven by variable performance costs.

Proposition 3 is illustrated in Figure 7 by adding more OECD countries. This shifts the line that represents $E \hat{U}^{\prime}(1-0)$ clockwise (to the crossed lines) and thus widens the contagion range. With $J=10$ the contagion range widens by about $1 / 2$ of a percentage point, with the portfolio share invested in Mexico varying between 3.8 percent and 6.6 percent.

The total performance costs avoided by displaying contagion are small. When $J=20$, and assuming $\Theta=0^{*}$, the maximum cost paid for choosing the largest $\theta$ within the contagion range is $1 / 10$ of the mean portfolio return. Thus, contagion can potentially induce large capital flows in and out emerging markets even in the presence of small performance costs. The marginal cost, however, is large in the sense that it represents a punishment for poor performance equal to 15 times the difference between the mean return paid by the market and that paid by the investor's portfolio. Note also that the size of the contagion range converges to about 2.8 percentage points as $J$ approaches $\infty$.

Next we measure the capital flows triggered by performance costs. Assume that the investors' total wealth corresponds to the holdings of foreign equity by U.S. investors. The latest Benchmark Survey of U.S. holdings of Foreign Securities conducted by the Treasury Department reports that by endMarch 1994 the holdings of foreign equity by U.S. investors amounted to $\$ 566$ billion. The model predicts that with $J=20$ the fraction of U.S. foreign equity invested in Mexico fluctuates between 2.53 
and 5.31 percent. ${ }^{16}$ Thus, contagion triggered by performance costs can account for sudden capital flows in and out of Mexico as large as $\$ 15.7$ billion. Adding investment in bonds, the total foreign security holdings of U.S. investors reach about $\$ 870$ billion, and thus contagion could account for Mexican capital flows of up to $\$ 24.2$ billion. As noted earlier, flows of this magnitude can be an important determinant of balance-of-payments crises.

Figure 7 also illustrates the role that the assumed properties of the performance cost function play in generating the contagion range. Without performance costs, the model has a unique solution at the point where $E \hat{U}^{\prime}(1-0)$ crosses the horizontal axis. Moreover, even if performance costs existed, a unique equilibrium would still prevail if the marginal cost were equal to the marginal gain. The discontinuity of $\lambda^{\prime}$ at $\theta=\Theta$ is also critical. If $\lambda$ were a smooth upward-sloping function investors would choose a value of $\theta$ different from $\Theta$ and hence update the market portfolio until the market agrees on a portfolio so that $E \hat{U}^{\prime}(0)=\lambda^{\prime}(0=\Theta)=0$.

Figure 8 examines the sensitiveness of the results to changes in different parameters of the model: the marginal cost and gain, $\varphi$, the correlation of asset returns, $\eta$, the coefficient of absolute risk aversion $\gamma$, and the variances of asset returns, $\sigma_{J}$ and $\sigma_{i}$. The parameter variations are constrained to satisfy the second-order condition specified in Proposition 2. This analysis shows that the results are generally robust to parameter variations. Marginal costs in excess of 15 result in a larger range of contagion equilibria, while lower values obviously reduce it. The opposite holds as we vary the value of the marginal gain. The contagion range is maximized when there is no marginal gain. A higher degree of risk aversion reduces sharply the size of the contagion range, but values of $\gamma$ higher than $1 / 2$ are grossly inconsistent with data on the composition of actual portfolios. For risk aversion coefficients between the benchmark value (1/4) and 1/2 the reduction in the contagion range is modest, while the range widens considerably for risk aversion coefficients lower than 1/4. The correlation of returns does

\footnotetext{
${ }^{16}$ Interestingly, the Treasury's Survey estimates the U.S. holdings of Mexican equity at 6.2 percent of the total holdings of foreign equity by U.S. investors.
} 
not affect noticeably the size of the contagion range until it becomes unrealistically high The contagion range is a declining function of the variances of asset returns in Country $i$ and abroad. However, the effect of the variance of the world fund dissipates with as few as 10 countries, and the range narrows very slightly for values of $\sigma_{i}$ above the Mexican estimates used in Figure 7 (i.e. 46.2 percent). For $\sigma_{i}$ below 46 percent and $J=10$, the size of the contagion range widens very rapidly as $\sigma_{i}$ falls.

Despite the large capital flows that contagion can produce, the implied welfare costs are small. We measured welfare costs by the percentage change in consumption needed for a portfolio inside the contagion range to yield the same utility of the Pareto optimal portfolio chosen in the absence of performance costs (i.e. $\left.\theta^{*}\right)$, making use of the model's direct utility function: $-\exp (-\gamma C)$. The welfare costs are at most 2.5 percent, and for portfolio share variations of 100 basis points around $\theta^{*}$ the costs are actually smaller than $1 / 4$ of a percentage point.

\section{Concluding Remarks}

This paper proposes a model of portfolio choice with imperfect information in which financial globalization reduces incentives for incurring the costs of gathering and processing country-specific information and thereby strengthens contagion effects. This occurs because: (a) globalization may reduce the gains from paying fixed information costs, and (b) in the presence of variable performance costs, globalization widens the range of portfolios inside of which investors find it optimal to mimic market portfolios. Numerical simulations showed that these two frictions can be quantitatively significant and can induce large capital outflows unrelated to country-specific fundamentals.

The analysis shows that informational frictions per se cannot produce contagion. Contagion requires that these frictions be combined with particular institutional or regulatory features of financial markets. In the case of fixed information costs, the gain of paying for costly information declines as the market grows only if investors face short-selling constraints. In the case of variable performance costs, a contagion range of multiple optimal portfolios exists only if the structure of incentives is such that the marginal cost of being beaten by the market exceeds the marginal gain of beating the market. In this 
context, policies that otherwise may seem useful instruments to help contain the volatility of capital flows, such as short-selling constraints or regulations on average returns across institutional investors, can in fact contribute to exacerbate the problem.

The role of fixed information costs deserves further consideration. One could argue that any sensible fixed information cost would be a trivial amount as a fraction of the large absolute wealth invested in securities markets or managed by securities firms. While this point is well taken, it also has a strong potential for complicating the issue further, instead of resolving it. Consider, for example, that clusters of investors group into mutual funds up to the point that for them the fixed cost is indeed trivial, and hence become "sophisticated traders," while there remains a group of agents that acting in isolation find the cost prohibitive and thus invest in mutual funds. Aiyagari and Gertler (1998) and Calvo (1999) have shown that in a setting like this, if limits on short bond positions impose binding margin constraints on securities firms, there could be equilibria in which equity prices and equity holdings fluctuate more than predicted by "fundamentals" in response to systemic shocks to "sophisticated traders."

The informational frictions examined here are reminiscent of those driving the models of informational efficiency developed by Grossman and Stiglitz $(1976,1980)$. Our analysis differed in that we studied the implications of market size for the gain of gathering costly information in a partialequilibrium setting with exogenous asset returns. In contrast, the Grossman-Stiglitz result that incentives to gather costly information are reduced by the anticipation that prices may reveal that information emphasizes the general equilibrium determination of prices. Their argument suggests, however, that a general equilibrium extension of our model may yield even smaller gains of gathering costly information because endogenous changes in returns would reveal some or all of the costly information at no cost.

The findings of this paper raise the question of whether globalization is necessarily welfare improving, and suggest that capital controls may be desirable because of the welfare costs induced by contagion. Our model, however, is not well suited for tackling this issue because the inefficiencies produced by contagion (in a setting in which all agents are "globally diversified" investors marginally 
affected by runs on a particular country) resulted in trivial welfare costs. The welfare costs of volatile capital flows may increase significantly if one departs from this ideal world. One alternative is to consider distortions that lead to self-fulfilling crises. For example, in Calvo (1996) a sudden run on government bonds by global investors forces large tax hikes which in turn cripple the ability of the private sector to yield future tax revenue and lead to a self-fulfilling default on public debt. Another alternative is to consider an economy that depends on capital inflows to finance imports, and uses the latter as inputs in domestic production. Some agents in this economy derive income only from labor services and do not access global capital markets. This model would still have to be carefully studied, however, since welfare costs resulting from ruling out world asset trading to manage country-specific risk in conventional neo-classical models have been found to be trivial (see Mendoza (1991)). ${ }^{17}$

Further research is clearly needed before specific recommendations can be made on the nature and extent of limitations that are desirable to impose on capital mobility. We need to develop quantitative models that can take into account both the costs and benefits of the globalization of securities markets, and the potentially counterproductive features of instruments that could seem useful to lessen the volatility of capital flows, such as short-selling and margin-call constraints. In the final analysis, the dismal economic performance of the developing world during the 1980s serves as a dramatic reminder of the fact that simply shutting down or limiting access to capital markets can have catastrophic consequences. In light of the events of recent years, however, non-intrusive regulations like the automatic trading halts at work in the New York Stock Exchange are difficult to disagree with.

We started the paper by quoting Keynes's and, given our findings and the above policy discussion, it seems appropriate to end the paper by quoting Keynes again:

"When the capital development of a country becomes a by-product of the activities of a casino, the job is likely to be ill-done...It is usually agreed that casinos should, in the public interest, be inaccessible and expensive (Keynes (1936), p. 159).

\footnotetext{
${ }^{17}$ This applies only to models in which growth and fluctuations are unrelated. If volatility affects growth, the gains of diversification can be large (see Obstfeld (1994) and Mendoza (1997)).
} 


\section{References}

Aiyagari, Rao and Mark Gertler (1998), "Overreaction of Asset Prices in General Equilibrium," forthcoming, Journal of Economic Dynamics

Banerjee, Abhijit V. (1992), "A Simple Model of Herd Behavior,"Quarterly Journal of Economics, v. CVII, pp. 797-817.

Bikhchandani, Sushil, David Hirshleifer, and Ivo Welch, (1992), "A Theory of Fads, Fashion, Custom, and Cultural Change as Informational Cascades," Journal of Political Economy, V. 100, pp.992-1026.

Bohn, Henning and Linda L. Tesar (1994), Can Standard Portfolio Theory Explain International Portfolio Investment?", mimeo, Dept. of Economics, University of California-Santa Barbara.

Calvo, Guillermo A. (1998), "Varieties of Capital Market Crises," in G. Calvo and M. King (eds.) The Debt Burden and its Consequences for Monetary Policy, Proceedings of a Conference held by the International Economic Association at the Deutsche Bundesbank, London, Macmillan. , (1999), “Understanding The Russian Virus,” mimeo, University of Maryland

Calvo, Guillermo A. and Enrique G. Mendoza, (1996) "Mexico's Balance-of-Payments Crisis: A Chronicle of a Death Foretold," Journal of International Economics, November.

Calvo, Sara and Carmen M. Reinhart (1995), "Capital Flows to Latin America: Is there Evidence of Contagion Effects." Mimeo, World Bank, Washington D.C..

Erb, Claude B., Campbell R. Harvey, and Tadas E. Viskanta (1996), "Expected Returns and Volatility in 135 Countries," Journal of Portfolio Management, v. 22, no. 3, pp. 46-58.

Frankel, Jeffrey A. and Sergio L. Schmukler, (1996), "Country Fund Discounts, Asymmetric Information, and the Mexican Crisis of 1994: Did Local Residents Turn Pessimistic Before International Investors"?, mimeo, University of California at Berkeley.

Grossman, Sanford J. and Joseph E. Stiglitz, (1976), "Information and Competitive Price Systems," American Economic Review, v. 66, pp. 246-253.

and _ (1980), "On the Impossibility of Informationally Efficient Markets," American Economic Review, v. 70, pp. 477-498

Keynes, John Maynard (1936), The General Theory of Employment, Interest, and Money, Harcourt, Brace, and Co., New York.

Lewis, Karen K. (1995), "Stocks, Consumption, and the Gains from International Risk-Sharing," mimeo, Wharton School of Business, University of Pennsylvania.

Mendoza, Enrique G., (1991), "Capital Controls and the Dynamic Gains from Trade in a Business Cycle Model of a Small Open Economy," IMF Staff Papers, v. 38, 480-505. 
Obstfeld, Maurice (1994), "Risk-Taking, Global Diversification, and Growth," American Economic Review, v. 84, pp. 1310-1330.

Pritsker, Matt G. (1994), "The Value of Information to an Individual Agent," mimeo, Board of Governors of the Federal Reserve System, Washington D.C.

Scharfstein, David S. and Jeremy C. Stein (1990), "Herd Behavior and Investment," American Economic Review, v. 80, pp.465-479.

Shiller, Robert J. (1995), "Conversation, Information, and Herd Behavior," American Economic Review: Papers and Proceedings, May.

and John Pound (1986), "Survey Evidence on Diffusion of Interest Among Institutional Investors," NBER working paper No. 1851.

and John Pound (1987), "Are Institutional Investors Speculators," Journal of Portfolio Management, Spring, pp.46-52.

Tesar, Linda L. and Ingrid M. Werner (1994), "U.S. Equity Investment in Emerging Stock Markets," mimeo, Dept. of Economics, University of California-Santa Barbara. 
Figure 1

Variability of Country Credit Ratings

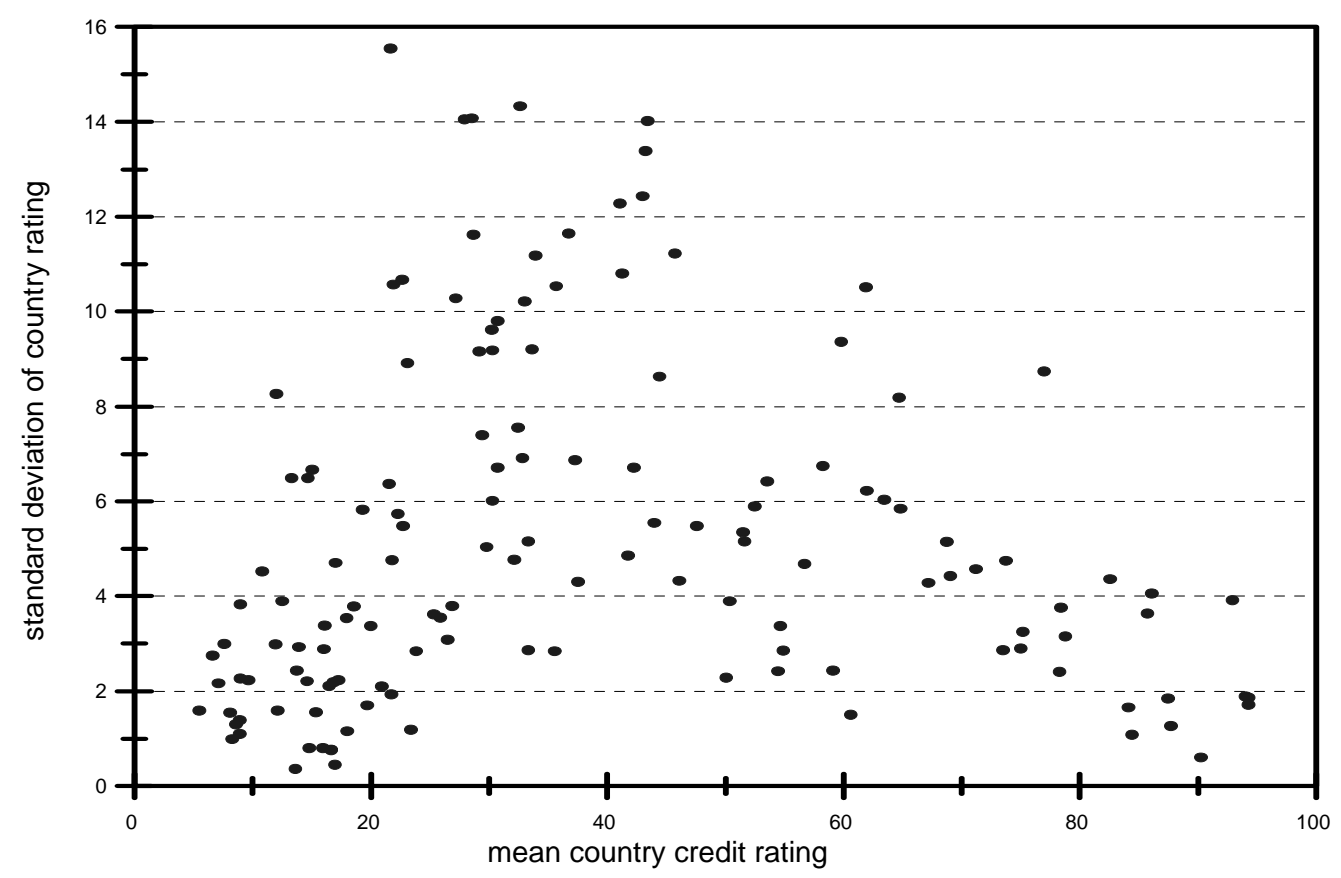

Figure 2.

Variability of OECD and Latin American Credit Ratings

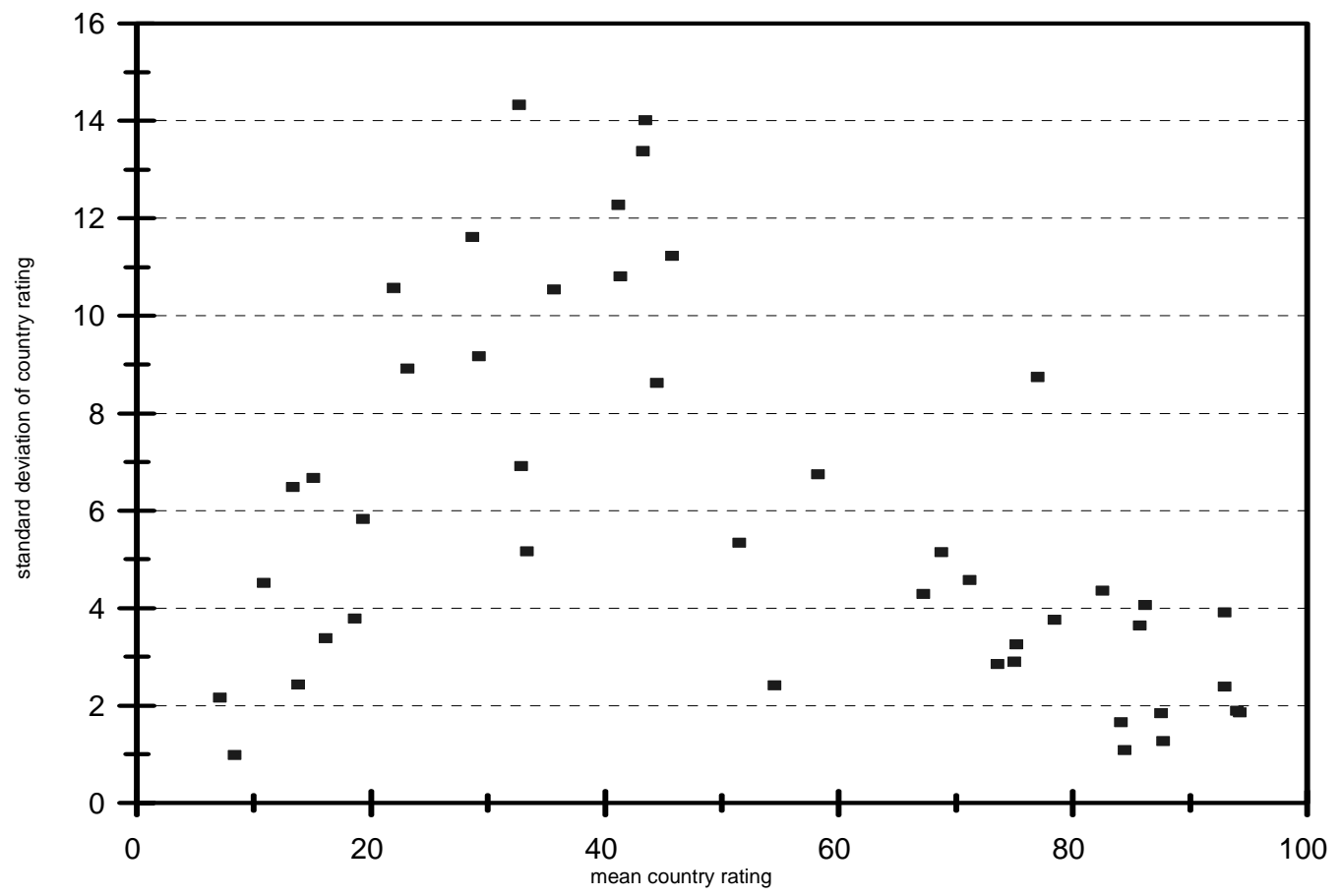


Figure 3.

Updates of the Mean and Standard Deviation of Returns

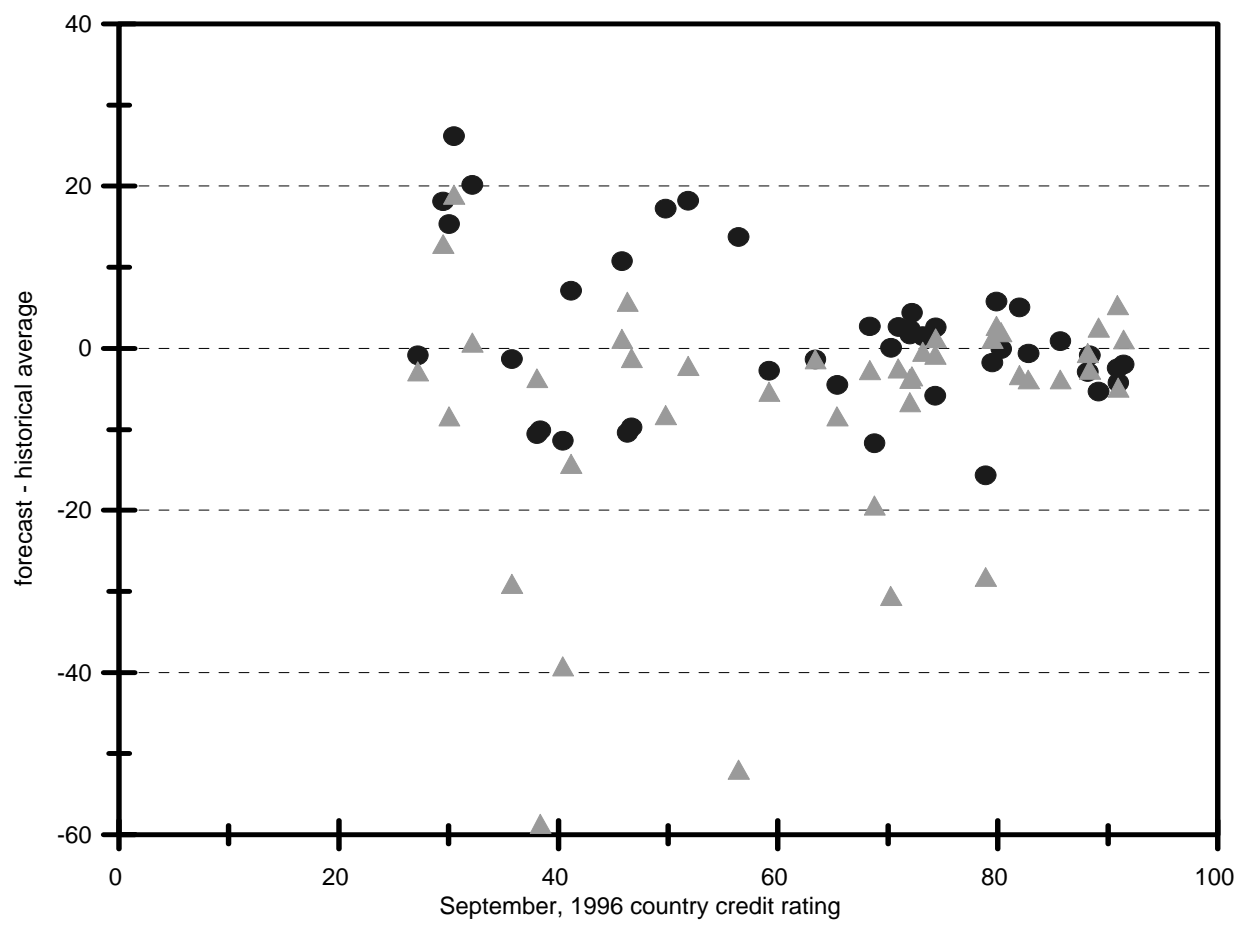

mean

standard deviation 
FIGURE 4

GAIN OF INFORMATION GATHERING AND MARKET SIZE: CASE I

Smallest Rumo

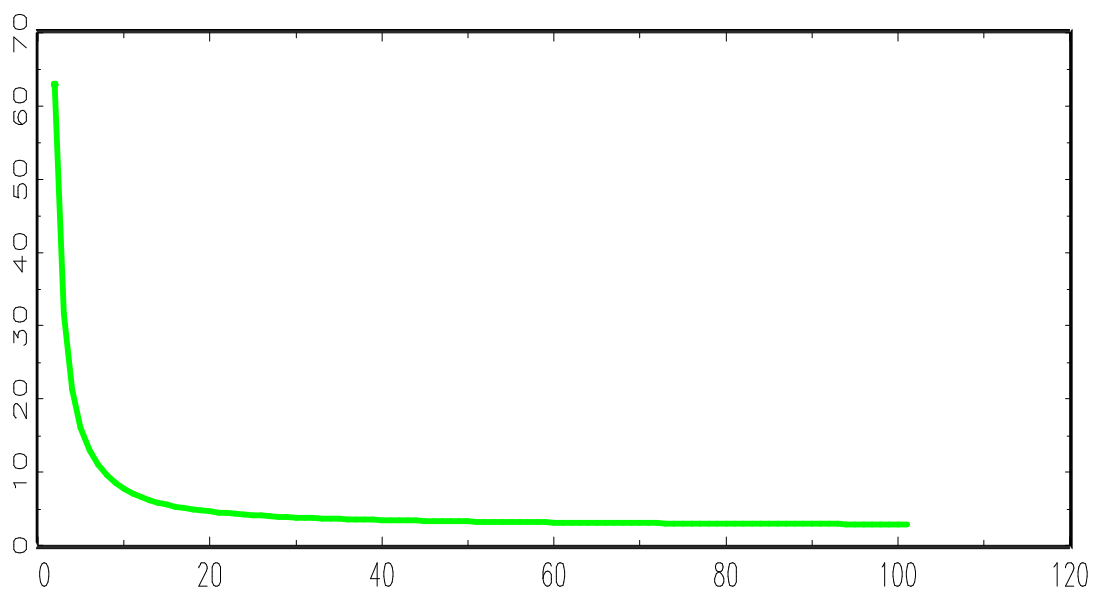

Rumor equal to World Mean Return

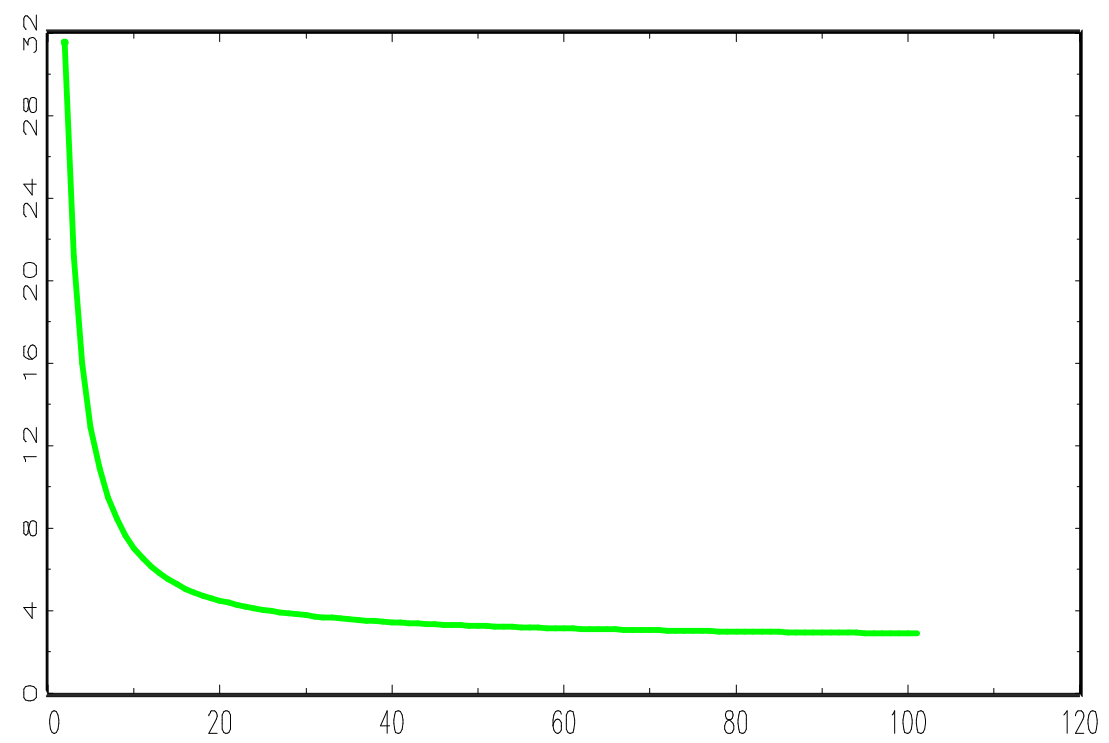

Largest Rumor

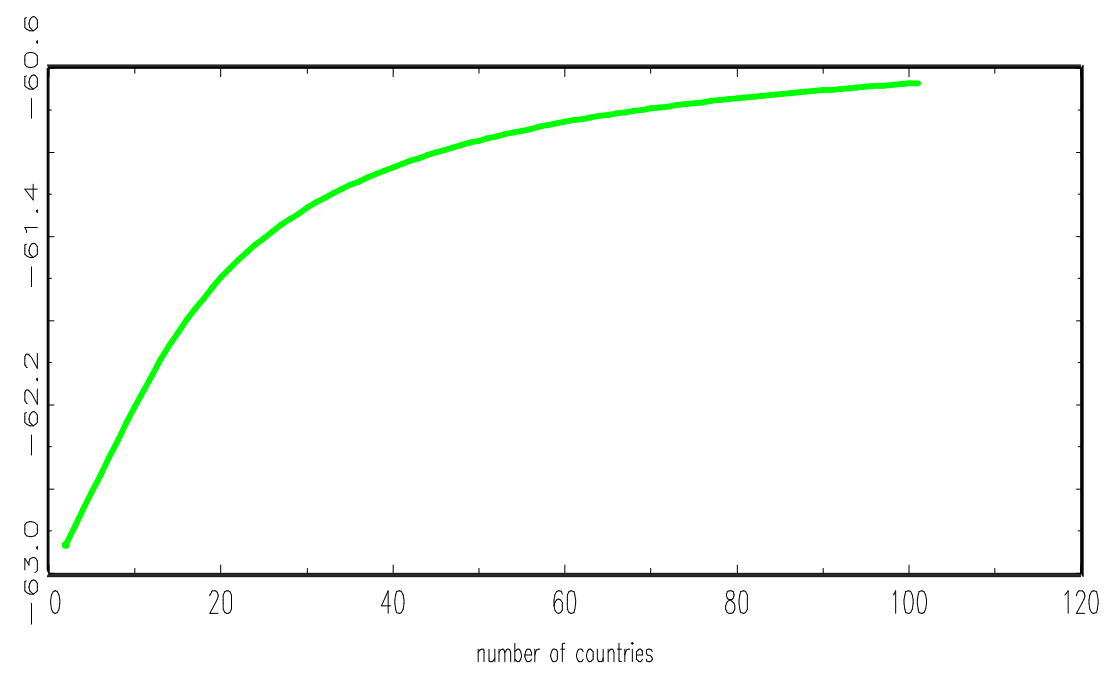


FIGURE 5

GAIN OF INFORMATION GATHERING AND MARKET SIZE: CASE ॥

Smallest Rumor

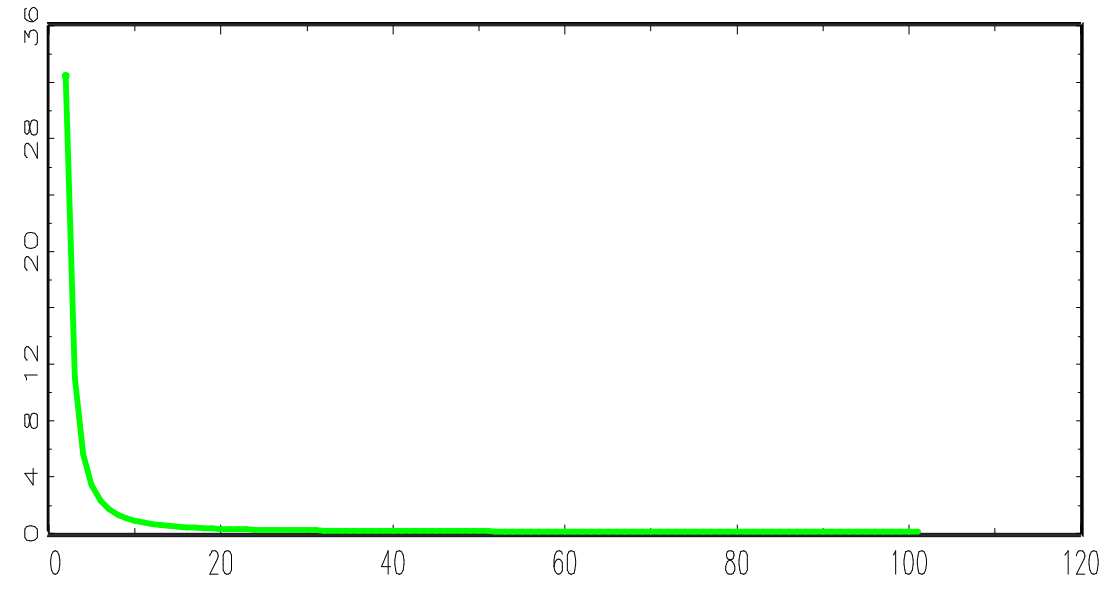

Rumor equal to World Mean Return

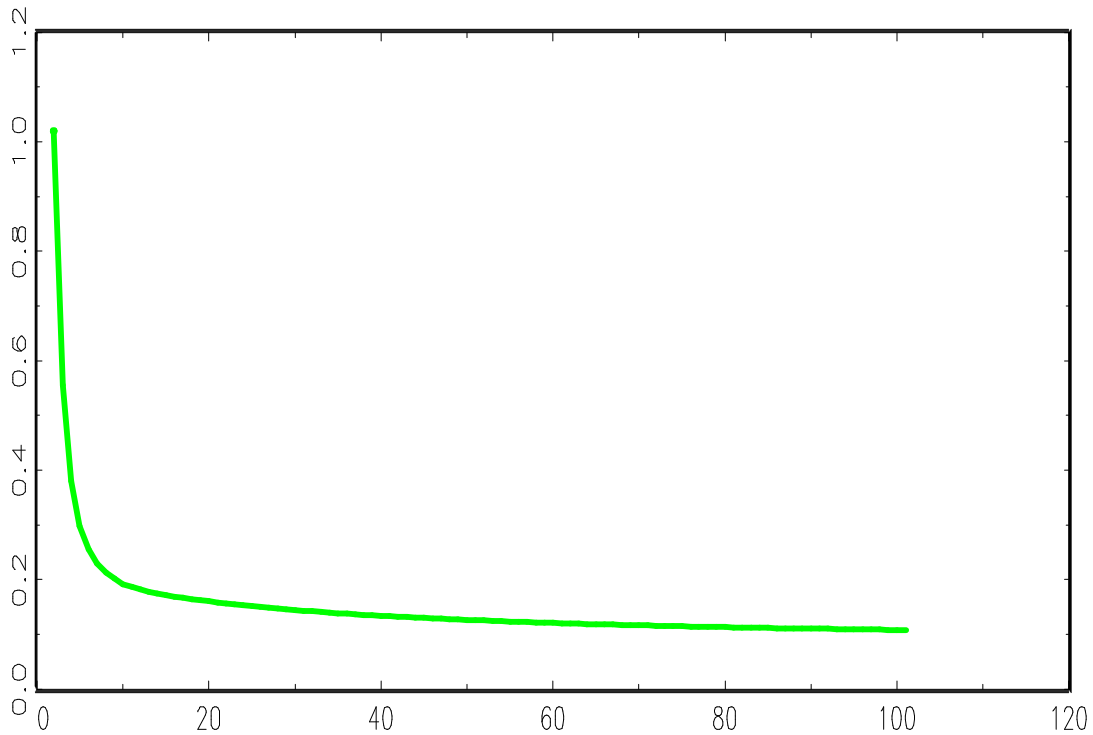

Largest Rumor

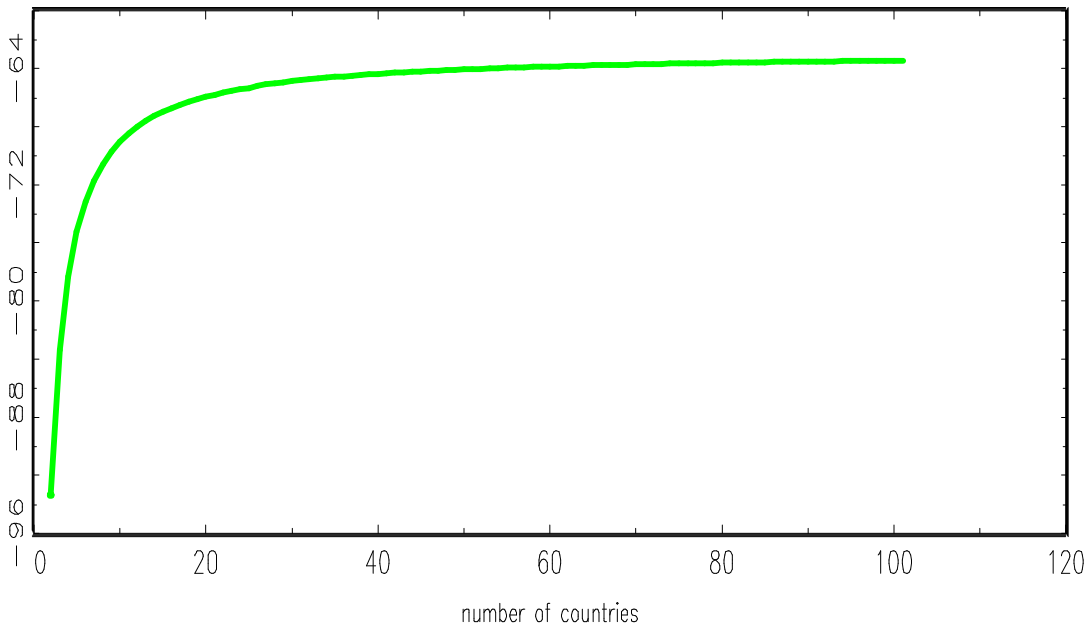


FIGURE 6

GAIN OF INFORMATION GATHERING AND MARKET SIZE: CASE III

Smallest Rumor

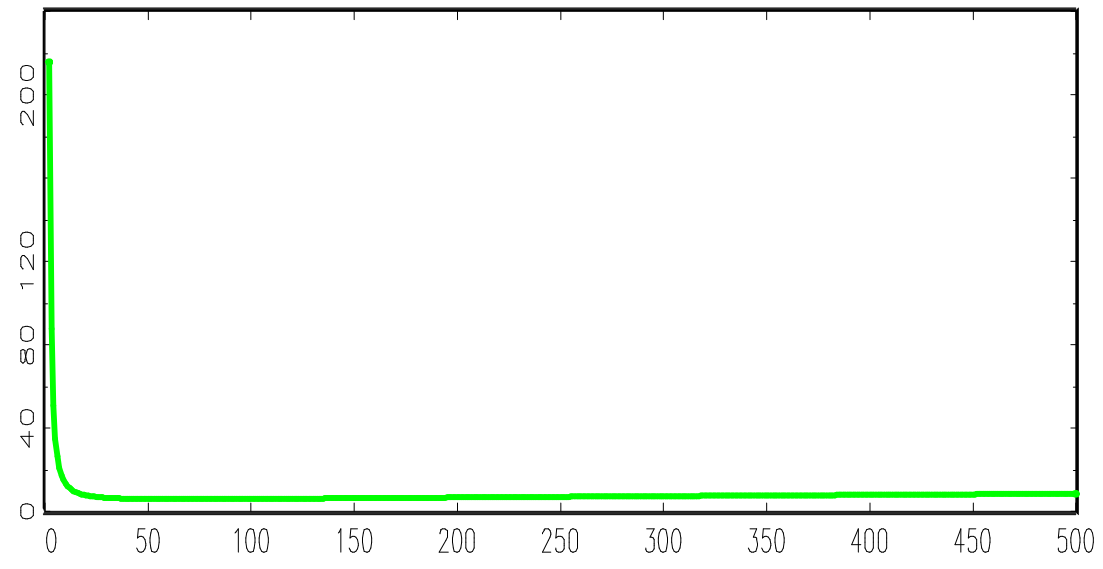

Rumor equal to World Mean Return

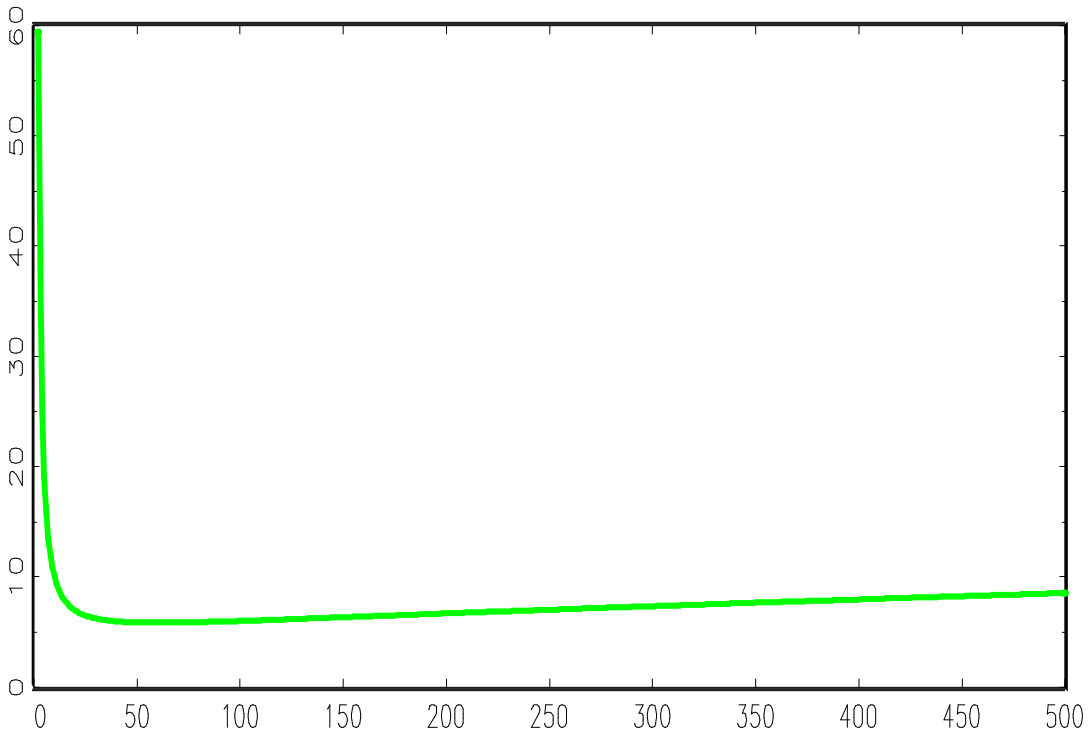

Largest Rumor

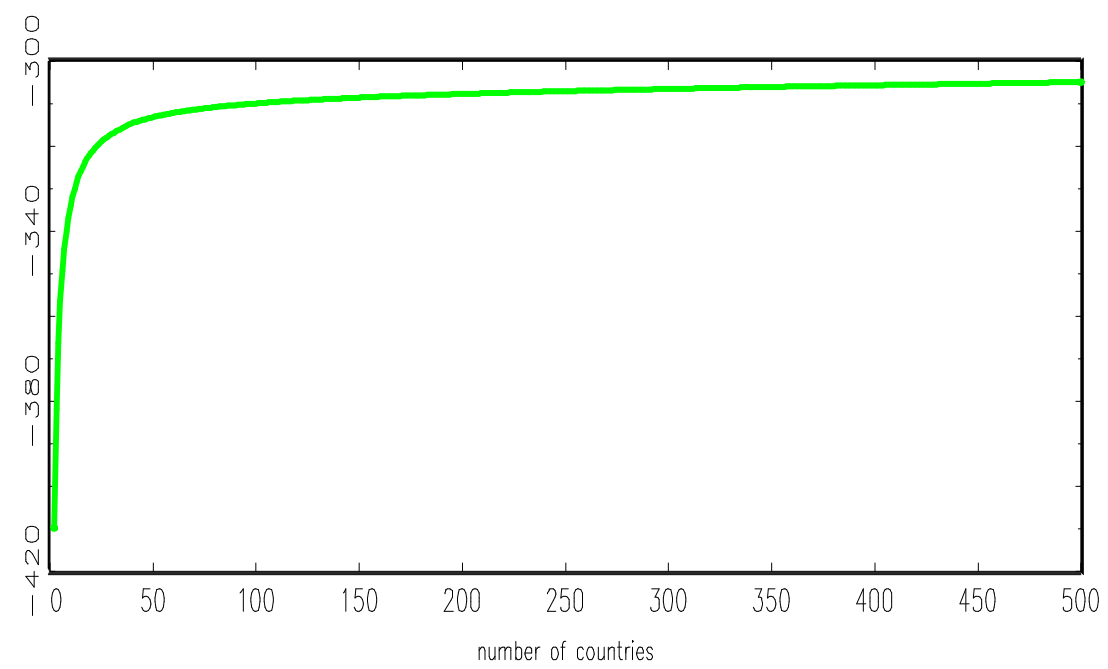


Figure 7. The Range of Multiple Optimal Portfolios in the Presence of Performance Costs

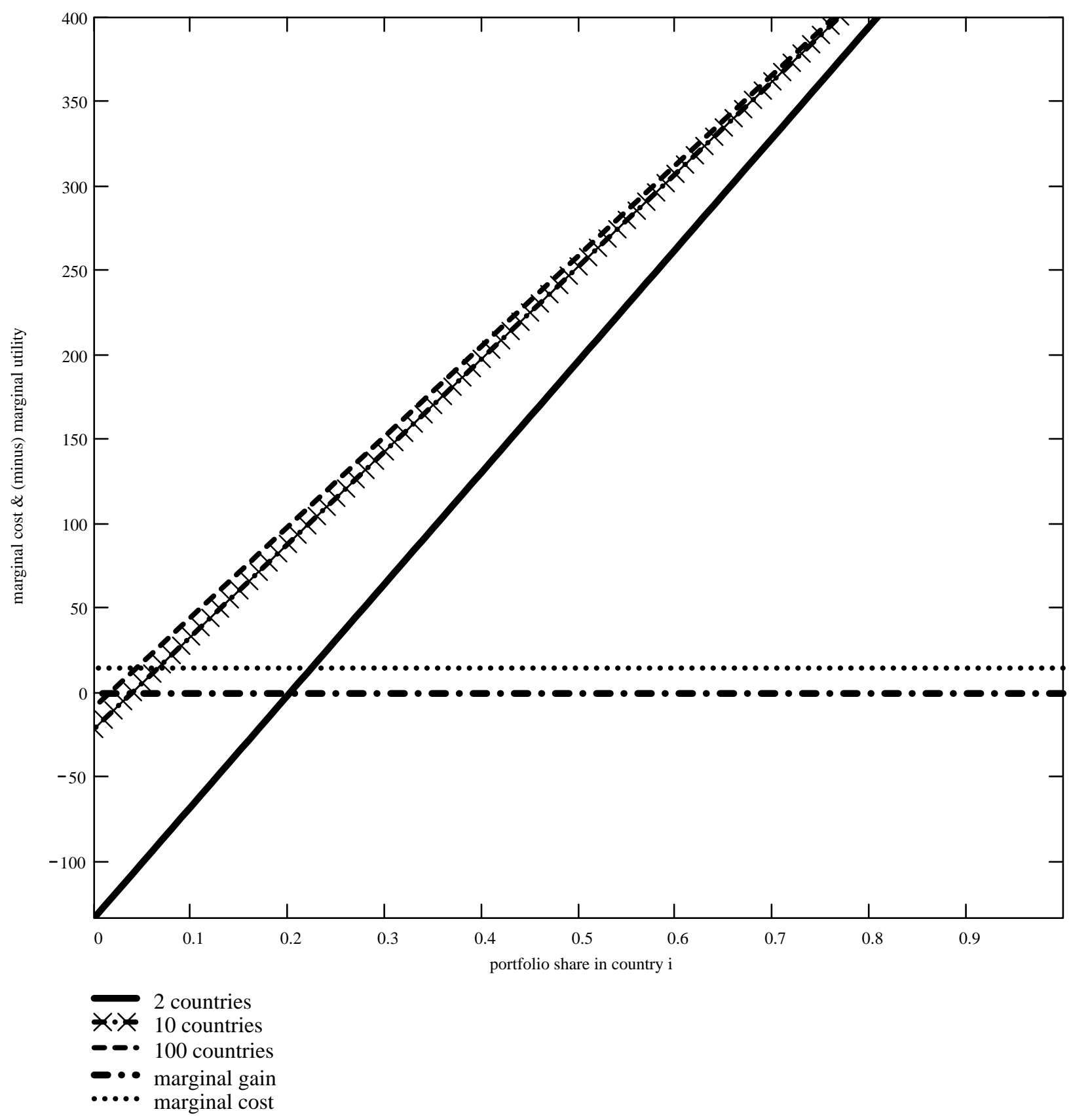


Figure 8. Size of the Range of Multiple Optimal Portfolios for Alternative Parameter Values
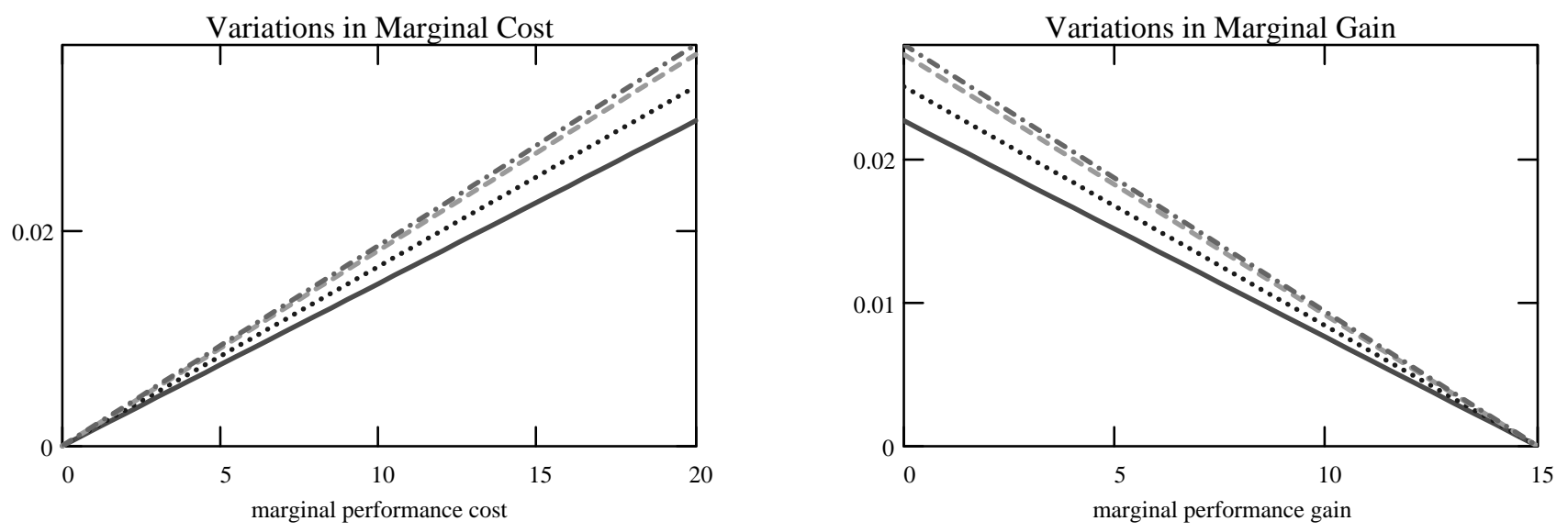

$\begin{array}{ll}-\ldots . . & 2 \text { countries } \\ \cdots- & 3 \text { countries } \\ -- & 10 \text { countries } \\ -\cdots & 200 \text { countries }\end{array}$

- 2 countries

..... 3 countries

- 10 countries

-.-. 200 countries
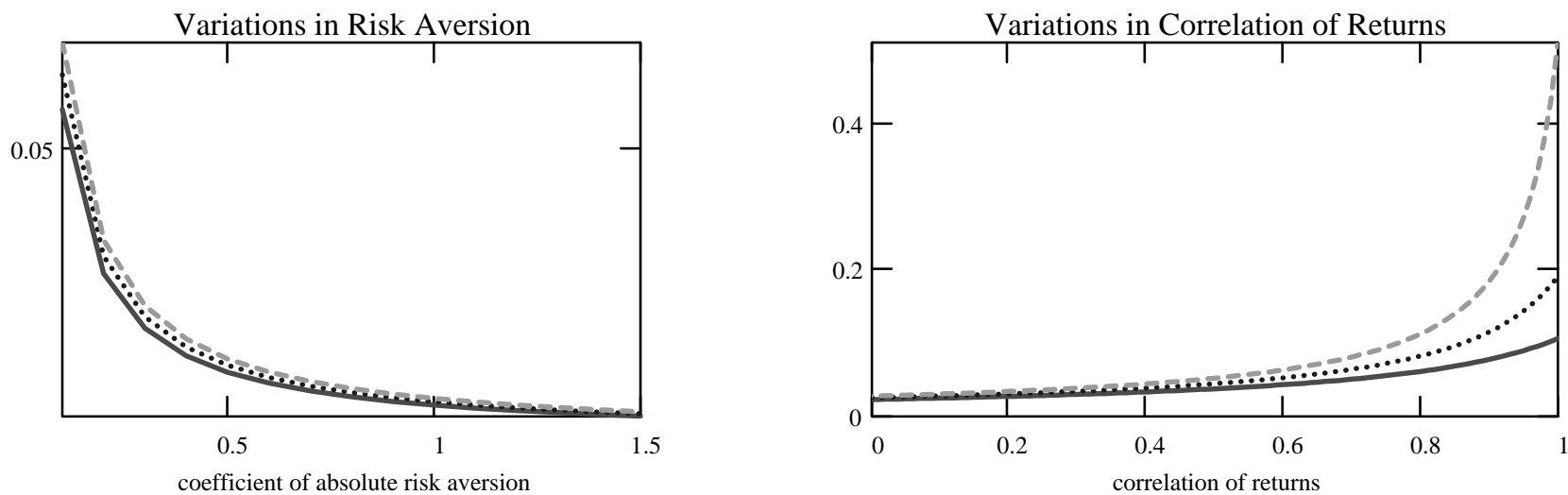

2 countries

….. 3 countries

$-\infty 10$ countries

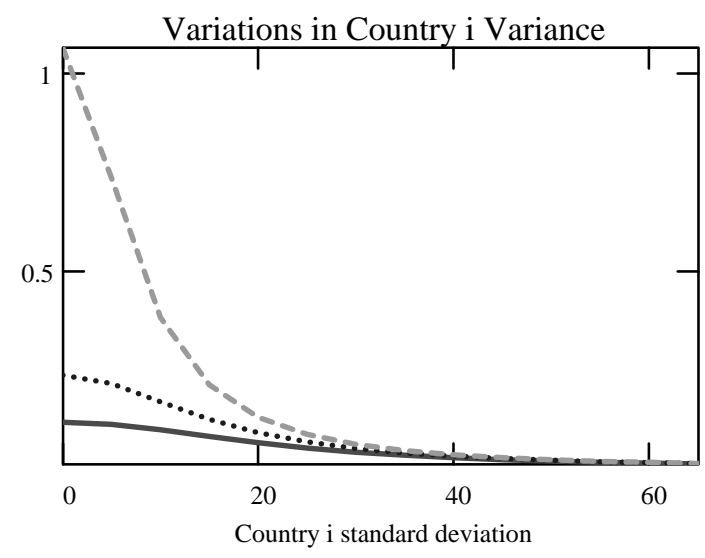

2 countries

…... 3 countries

$-\infty 10$ countries

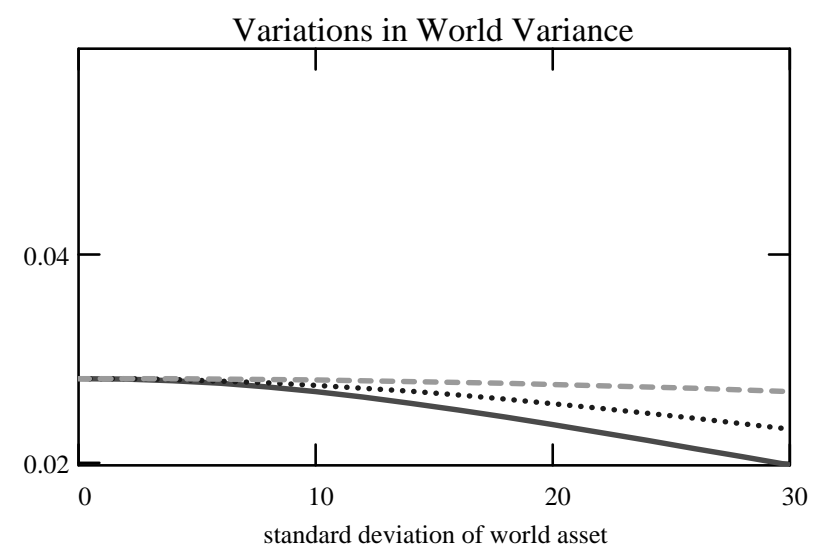

$\begin{array}{ll}-\ldots . & 2 \text { countries } \\ \ldots- & 3 \text { countries } \\ \ldots & 10 \text { countries }\end{array}$

- 2 countries

…. 3 countries

$-\infty \quad 10$ countries 